STEVE J. DAVIS

University of Chicago

JOHN HALTIWANGER

University of Maryland

\title{
Wage Dispersion between and within U.S. Manufacturing Plants, $1963-86$
}

THIS PAPER EXPLOITS a rich and largely untapped source of information on the wages and other characteristics of individual manufacturing plants to cast new light on recent changes in the U.S. wage structure. Our primary data source, the Longitudinal Research Datafile (LRD), contains observations on more than 300,000 manufacturing plants during census years $(1963,1967,1972,1977,1982)$ and 50,000-70,000 plants during intercensus years since 1972. We use the information in the LRD to investigate changes in the plant-wage structure over the past three decades. We also combine plant-level wage observations in the LRD with wage observations on individual workers in the Current Population

In preparing the data for this study we have greatly benefited from the assistance of Bob Bechtold, Tim Dunne, James Monahan, Robert McGuckin, and other Census Bureau employees at the Center of Economic Studies. We thank Chinhui Juhn and Kevin Murphy for providing the March CPS data, Erica Groshen for providing the January 1977 CPS supplement, and Barry Hirsch for providing much of the union data. We also thank Tim Dunne, Larry Katz, Frank Levy, Richard Murnane, Robert Topel, and the participants of the December 1990 Micro BPEA conference and workshops at the University of Chicago and Yale University for helpful comments on earlier drafts. Scott Schuh provided exceptionally able research assistance. We gratefully acknowledge research support provided by the National Science Foundation, a Joint Statistical Agreement between the Census Bureau and the University of Maryland, and the Graduate School of Business at the University of Chicago. 
Survey (CPS) to estimate the between-plant and within-plant components of overall wage dispersion. ${ }^{1}$

\section{Introduction and Background}

The main phenomenon motivating our investigation is the dramatic, continuous rise in wage inequality in the United States since the late 1960s. Most of the rise is accounted for by inequality increases within groups of workers defined by experience, education, and gender. We interpret the large and growing role for inequality within groups of workers with similar characteristics, as observed in household surveys, as strong motivation for our investigation into the relationship between wages and observable plant characteristics. Since observable worker characteristics fail to explain the bulk of both the level and rise in wage inequality, it is natural to inquire into the role of employer characteristics. We show that there have been striking changes in the distribution of observable plant characteristics and in the wages associated with plant characteristics since the late 1960s.

The paper proceeds as follows. In the balance of the introduction, we review the major changes in the U.S. wage structure over the past three decades, show that the manufacturing sector also experienced large increases in overall and within-group wage inequality, and document some major institutional and structural changes in the manufacturing sector. We also discuss the main hypotheses about rising wage inequality that play a role in the ensuing analysis. The following section combines information from household and establishment surveys to

1. We make no attempt in this paper to systematically survey the large body of existing research on the plant-wage structure, but a few remarks are in order. First, our investigation differs from previous work on the plant-wage structure with respect to the superior size, scope, and (in many respects) quality of the data set we bring to the analysis. Dunne and Roberts (1990) are the only other researchers to exploit a large segment of the LRD for analysis of the wage structure. Recent papers by Groshen (1991a, 1991b) that use plantlevel data focus on many of the same issues that we take up in this paper. Second, employer size is found to be an important correlate of wages across a wide range of previous studies, a result that emerges strongly in the results we report. An important recent study by Brown and Medoff (1989) contains extensive references to the literature on employer size-wage differentials. Third, very few previous studies examine time-series changes in the plantwage structure with an eye toward explaining rising wage inequality. Groshen (1991b) is the only exception known to us. 
decompose the total variance of wages into between-industry, betweenplant, and within-plant components for both production and nonproduction workers. This decomposition allows us to measure the components of rising wage inequality and to begin evaluating competing explanations for the rise. Next we describe alternative explanations for the findings reported in the paper. We discuss reasons for wage differentials across plants, and we outline a simple competitive model that illustrates the contrasting implications of product demand shifts and skill-biased technical change for changes in the wage structure. We also discuss the possible role of noncompetitive and institutional factors in the growth of wage dispersion. In the next section, we investigate the role of observable plant characteristics in the distribution of wages across plants, using time-series changes in the plant-wage structure to help identify the driving forces behind rising wage inequality. Finally we investigate the impact of changing trade patterns and unionization rates on the plant-wage structure.

\section{The Changing U.S. Wage Structure and Alternative Explanations}

The U.S. economy experienced pronounced shifts in the structure of wages over the past three decades. Wage differentials between more and less experienced workers widened substantially between 1963 and 1987, with the sharpest increases occurring during the 1980s. The college wage premium rose between 1963 and 1971, fell between 1971 and 1979 , and then rose dramatically during the 1980s. The wage gap between men and women changed little from 1963 to 1979 but shrank significantly during the $1980 \mathrm{~s}^{2}$

On net, these between-group changes had little effect on overall wage inequality during the 1960 s and 1970 s, but after 1979 they contributed toward an increasingly unequal distribution of wages. Wage inequality within groups of workers defined by experience, education, and gender rose continuously after 1970 . While within-group wage inequality increased at a smooth pace over the past two decades, the increase in overall wage inequality accelerated during the 1980 s as the experience,

2. Katz and Murphy (1990) document all of these changes. Other recent research documenting some or all of these changes includes the papers by Blackburn, Bloom, and Freeman (1989); Bluestone (1989); Bound and Johnson (1989); Juhn, Murphy and Pierce (1989); Levy (1989); Murphy and Welch (1991); and Katz and Revenga (1989). 
education, and within-group components each made substantial contributions to the growth of wage inequality. ${ }^{3}$

Researchers have advanced several hypotheses to explain these large changes in the wage structure. Observed fluctuations in the growth rate of the relative supply of college graduates, coupled with the assumption of steady relative demand growth for more educated workers, provide a simple and coherent explanation for movements in the college wage premium over the past thirty years. ${ }^{4}$ The continuous expansion of experience differentials and within-group inequality over the past twenty years also point toward explanations that stress steady relative demand growth of more highly skilled workers.

One set of explanations for the relative demand growth of high-skill workers centers around the consequences of an increasingly integrated world economy. U.S. exports plus imports rose from less than 13 percent to more than 24 percent of gross national product between 1970 and $1988 .{ }^{5}$ Since less-skilled workers are disproportionately employed in import-intensive sectors, this pronounced shift toward a more open economy has decreased the relative demand for less skilled U.S. workers. Borjas, Freeman, and $\mathrm{Katz}^{6}$ analyze the labor skill content embodied in U.S. flows of traded goods and immigrants and conclude that these flows greatly increased the effective supply of less educated workers during the $1980 \mathrm{~s}$. They attribute one-third of the rising college wage premium between 1980 and 1987 to the effects of trade and immigration flows.

A second set of explanations for the relative demand growth of highskill workers centers around skill-biased technical change. The spread of computer technology in the workplace and greater reliance on more flexible production techniques are factors that have perhaps increased the relative demand for more skilled workers. ${ }^{7}$ At least three aspects

3. Juhn, Murphy, and Pierce (1989).

4. Katz and Murphy (1990).

5. Abowd and Freeman (1990).

6. Borjas, Freeman, and Katz (1991).

7. There is considerable debate about the impact of changing technology on skill requirements. While substantial evidence shows that skill requirements have increased, there is also evidence that technological advances sometimes reduce skill requirements. For a discussion of this debate and references related to the impact of changing technology on skill requirements, see Levy and Murnane (1991). We return to this issue in "Explanations for Wage Differences across Plants.", 
of recent changes in the wage structure point toward an important explanatory role for skill-biased technical change. First, the timing of changes in education differentials contrasts sharply with the timing of increases in experience differentials and within-group inequality. This contrast indicates that these dimensions of worker skill are not close substitutes in production, and that movements in the various skill premia are driven by different disturbances. Second, the timing of trade-related disturbances, which are concentrated in the 1980s, do not conform well to the smooth growth of within-group wage inequality over the past two decades. Other product demand disturbances of sufficient magnitude to plausibly explain the large increases in within-group wage inequality are not apparent. ${ }^{8}$ Third, since the timing and magnitude of increases in within-group inequality are roughly age-neutral, it is unlikely that they are driven by an increasing dispersion of unobservable worker quality attributes related to, say, increasingly unequal educational quality. ${ }^{9}$ We conclude from these observations that skill-biased technical change will play a major role in any satisfactory neoclassical explanation for recent changes in the wage structure.

An alternative, and complementary, approach to explaining recent increases in wage inequality stresses institutional changes in the labor market rather than demand and supply factors. The view that unionism might have potentially important effects on overall wage inequality has a long tradition in labor economics. ${ }^{10}$ It is often argued that unions narrow the wage gap between less and more skilled workers and sometimes argued that they reduce the dispersion of wages among workers with similar characteristics. ${ }^{11}$ Accordingly, the dramatic fall in union density in recent decades suggests that it might be an important contributor to widening experience difierentials and growing within-group wage inequality. ${ }^{12}$ Alternatively, the decline in union density might reflect deeper economic factors related to changes in the organization and nature of production activity. Under this interpretation declines in

8. For evidence on the inability of interindustry shifts in the structure of product demand to explain the relative decline in demand for less-skilled workers, see Juhn, Murphy and Pierce (1989, sec. 5); and Katz and Murphy (1990, sec. 5).

9. Juhn, Murphy, and Pierce (1989).

10. Freeman and Medoff (1984); and Lewis (1986).

11. Freeman $(1980,1982)$.

12. Freeman (1988). 
Figure 1. Inequality Measures for Hourly Wages in U.S. Manufacturing, 1975-88

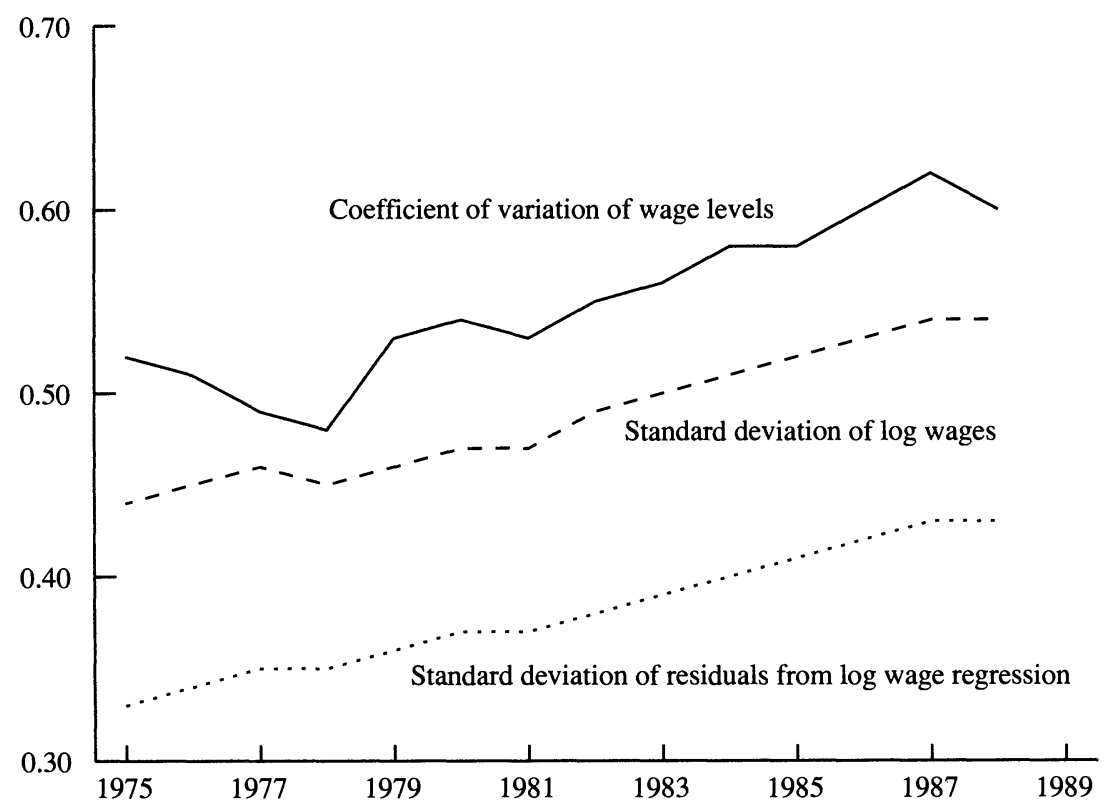

Source: Authors' calculations from March files of Bureau of the Census, Current Population Survey (Department of Commerce).

union density, and their relationship to the evolution of the wage structure, provide additional information that can help identify the deeper changes that have affected both unionism and the wage structure.

\section{The Changing Wage Structure in the Manufacturing Sector}

Since we focus on the manufacturing sector in this paper, it is important to establish at the outset the differences and similarities between developments in this sector and developments in the economy as a whole. Figure 1 displays the evolution of three inequality measures for hourly manufacturing wages from 1975 to 1988 . We computed these measures from the observations on annual hours worked and annual salary and wages in the 1976-1989 Annual Demographic Supplements to the March CPS. ${ }^{13}$ Wage figures are expressed in 1982 dollars using

13. We restrict our March CPS sample to manufacturing workers who report hourly wages greater than 75 percent of the minimum and less than $\$ 250$ in 1982 dollars. Each 
the GNP implicit price deflator for personal consumption expenditures. Major changes in CPS reporting and imputation procedures make it difficult to construct satisfactory inequality measures for hourly wages prior to 1975. Accordingly, here and throughout the paper, we do not report CPS-based results for years prior to $1975 .{ }^{14}$

The solid curve in figure 1 shows that overall wage inequality in the manufacturing sector, as measured by the hours-weighted standard deviation of log hourly wages, rose by 20 percent from 1975 to 1988 . The bottom curve, which depicts the standard deviation of log wage regression residuals, illustrates the importance and dramatic growth of wage inequality within experience-education-gender groups. The residuals are computed from yearly cross-sectional regressions of log wages on years of schooling, four schooling class variables, years of schooling interacted with the schooling class variables, sex, and a quartic in experience fully interacted with the other regressors. Withingroup hourly wage inequality accounted for 74 percent of overall inequality in 1975 and 78 percent in 1988. Between 1975 and 1988, within-group inequality rose by 25 percent, accounting for 95 percent of the rise in overall inequality. Thus, the standard explanatory variables available in household surveys account for a fairly small, and declining, fraction of total wage variation. In this respect, developments in the manufacturing sector mirror developments in the economy as a whole.

Most previous studies of earnings inequality focus on the distribution of log wages. Given the information available in the LRD, we investigate the distribution of wages measured in natural units throughout the rest of the paper. The top curve in figure 1 shows that the coefficient of variation in raw wages rose by 19 percent between 1975 and 1988, slightly less than the rise in the standard deviation of log wages. There are minor differences in the two measures over short time periods, but the pronounced rise in wage inequality emerges clearly in both series. We conclude that differences in the unit of measurement should not seriously hamper comparisons between our findings and the results reported in previous research.

March file of the CPS contains information for the previous calendar year on roughly 12,000 to 15,000 manufacturing workers.

14. On the reporting and imputation changes in the CPS, see Lillard, Smith, and Welch (1986); and Juhn, Murphy, and Pierce (1989). 
Figure 2. Interindustry Wage Differentials, Production Workers, Fraction of Variance Not Accounted for by:

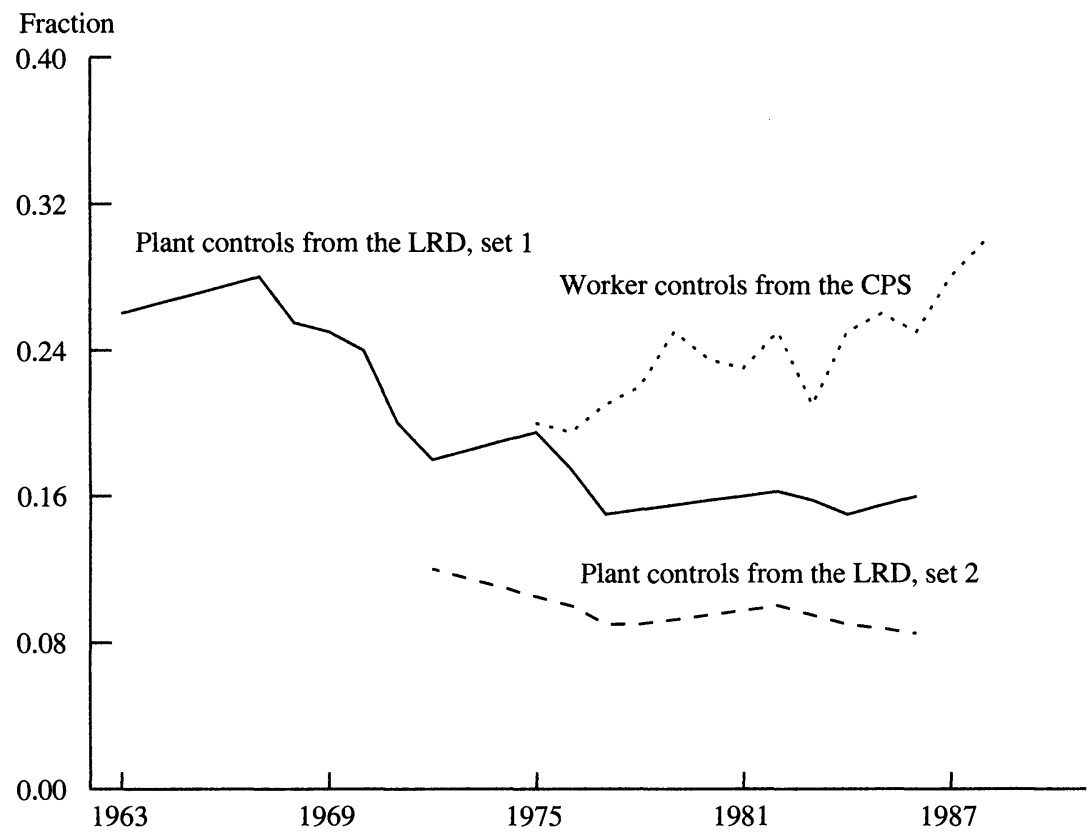

Note: See text for a description of regression controls.

One simple way to motivate our inquiry into the role of employer characteristics is to compare the information content of the LRD and CPS with respect to the ability of observable worker characteristics and observable plant characteristics to account for interindustry wage differentials. Since these wage differentials have been the focus of a large and controversial body of work in recent years, this comparison is intrinsically interesting as well. ${ }^{15}$

To carry out the comparison, we calculated the ratio of the hoursweighted variance of mean wages across industries to the same measure computed from the residuals in hours-weighted cross-sectional regressions on observable worker (CPS) or plant (LRD) characteristics. Reciprocals of these variance ratios, essentially the unexplained fraction of interindustry wage variation, are plotted in figure 2 . The LRD ratios are for selected years between 1963 and 1986 for one set of plant-level

15. Katz and Summers (1989). 
controls, and for selected years between 1975 and 1986 for a second, and more extensive, set of plant-level controls. To compute the CPS residuals, we regressed raw hourly wages on nine region dummies, sex, four schooling classes, years of schooling, years of schooling interacted with the schooling class variables, and a quartic in experience fully interacted with all other variables except region. To compute the LRD residuals corresponding to set 1 (the 1963-86 results), we regressed the mean plant wage on nine region dummies, three energy cost-share classes, five capital intensity classes, two ownership-type dummies, five product specialization classes, and a quartic in size with no interaction terms. For set 2 of the LRD plant controls (the 1975-86 results), we added three age classes, fully interacted the class variables, and interacted the quartic in size with the class variables. ${ }^{16}$

The results of the comparison are striking. In overlapping years, observable plant characteristics more successfully account for interindustry wage differentials than observable worker characteristics. The unexplained component of industry wage differentials in the CPS are two and one-half times as large as in the LRD using the more extensive set of plant controls. The unexplained component of industry wage differentials in the CPS rises from 14.5 percent in 1975 to 20.5 percent in 1988 . The unexplained component of industry wage differentials in the LRD falls dramatically from 1967 to 1972 and then falls slightly further by 1986 . In 1986, and with the extensive set of plant controls, the LRD accounts for all but 9 percent of the variance of industry wage differentials. Combined with the inability of observable worker characteristics to account for increases in manufacturing wage inequality, Figure 2 indicates that further study of the plant-wage structure is strongly warranted.

\section{Major Institutional and Structural Changes in the Manufacturing Sector}

We now document some major institutional and structural changes in the manufacturing sector that play a role in the ensuing analysis.

16. The plant-level variables are more fully defined later in the paper. Here and throughout the paper, we restrict the LRD sample to plants with a mean wage (by worker type) at least 75 percent of the minimum wage and no more than $\$ 250$ an hour in 1982 dollars. We also dropped plants with missing production worker observations on the plant characteristics used in this study. Appendix A provides information on sample counts before and after the imposition on selection criteria. 
Figure 3. Union Membership Density in the United States, 1960-88

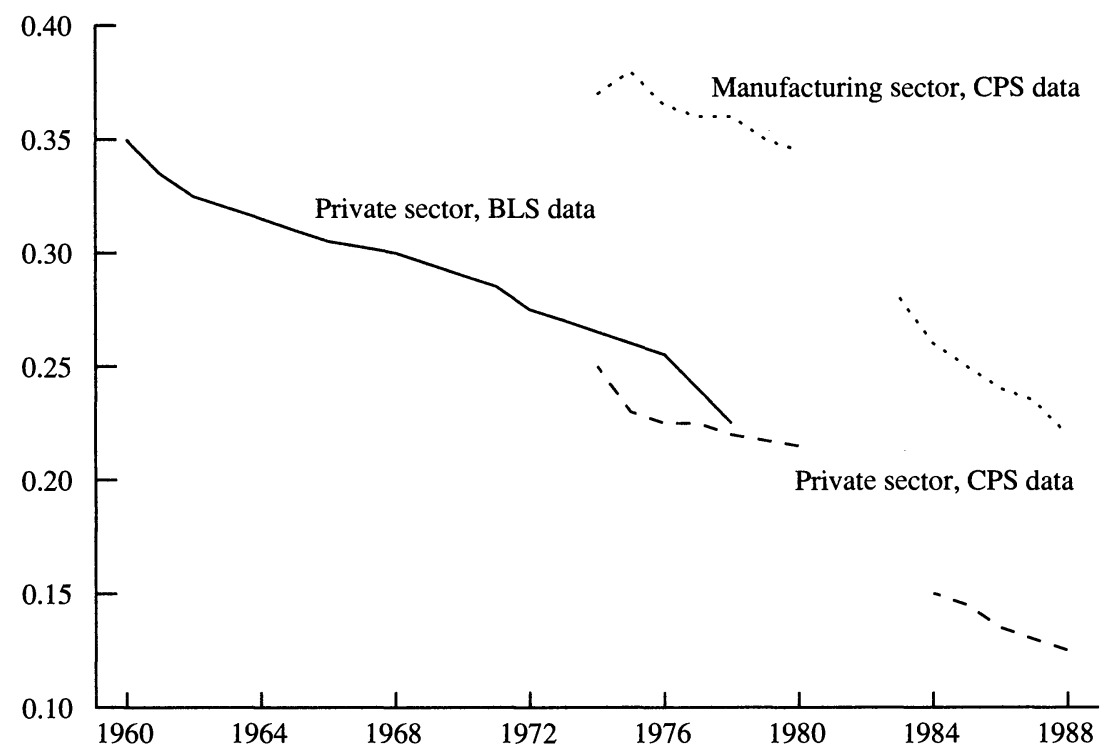

Sources: See text.

Where data are available, we also compare changes in the manufacturing sector to changes in the economy as a whole.

Figure 3 plots measures of union membership density in the private sector and the manufacturing sector of the U.S. economy. The Bureau of Labor Statistics (BLS) figures show a steep, continuous decline in private-sector union density from 1960 to 1978 . The CPS figures show a continuing pronounced decline through 1988. These figures also show a comparable decline in union density within the manufacturing sector since $1975 .{ }^{17}$ Given the numerous studies that find important connec-

17. The 1974 to 1980 CPS figures are from Kokkelenberg and Sockell (1985), who estimated union density as a fraction of the workers covered by the National Labor Relations Act. Since most managers and supervisors are not covered by the act, the Kokkelenberg and Sockell figures overstate union membership as a fraction of the private-sector work force and, at least for manufacturing, probably understate the decline in union density. The 1983 to 1988 CPS figures are from Curme, Hirsch, and Macpherson (1990). For the analysis in subsequent sections, we adjusted the Kokkelenberg and Sockell data to be comparable to the data of Curme and others, using 1974 data in Freeman and Medoff (1979). Freeman and Medoff estimate union density in a way comparable to the Curme data. 
Figure 4A. Distribution of Employees by Plant Size in the U.S. Private Sector, 1962-85

Mean

Standard deviation

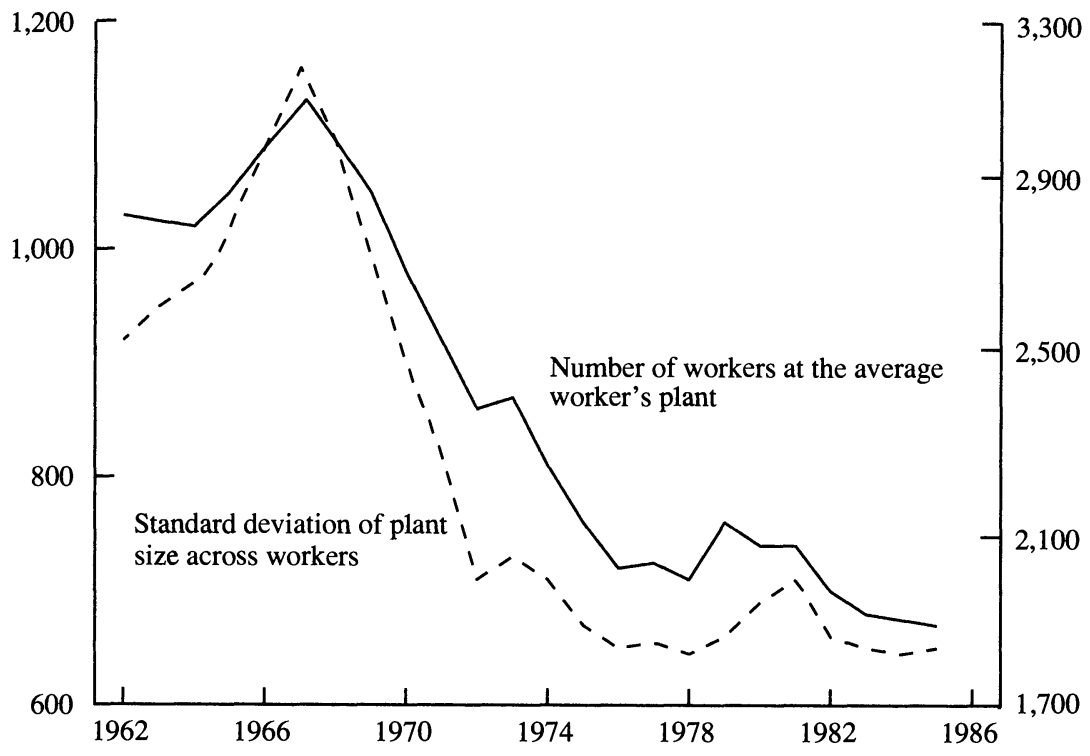

Source: Authors' estimates based on the Longitudinal Research Datafile and County Business Patterns Data.

tions between unionism and the wage structure, figure 3 suggests that the decline in unionism may be an important factor in recent changes in the wage structure.

Empirical studies consistently find higher wages at larger plants after controlling for observable worker characteristics and other observable plant characteristics. ${ }^{18}$ Some of our recent research documents major changes in the distribution of employees by plant size in the U.S. economy since $1967 .{ }^{19} \mathrm{We}$ summarize these changes in figures 4 . A and 4.B, which plot time series for the coworker mean (the number of

18. Brown and Medoff (1989) investigate explanations for size-wage differentials based on sorting by worker skill, compensating differentials, union effects, rent sharing, and efficiency wage considerations. They find supportive evidence only for explanations based on sorting by worker skill. We discuss sorting and other explanations for the size-wage differential in "Explanations for Wage Differences across Plants."

19. Davis and Haltiwanger (1989). 
Figure 4B. Distribution of Employees by Plant Size in U.S. Manufacturing, 1962-86

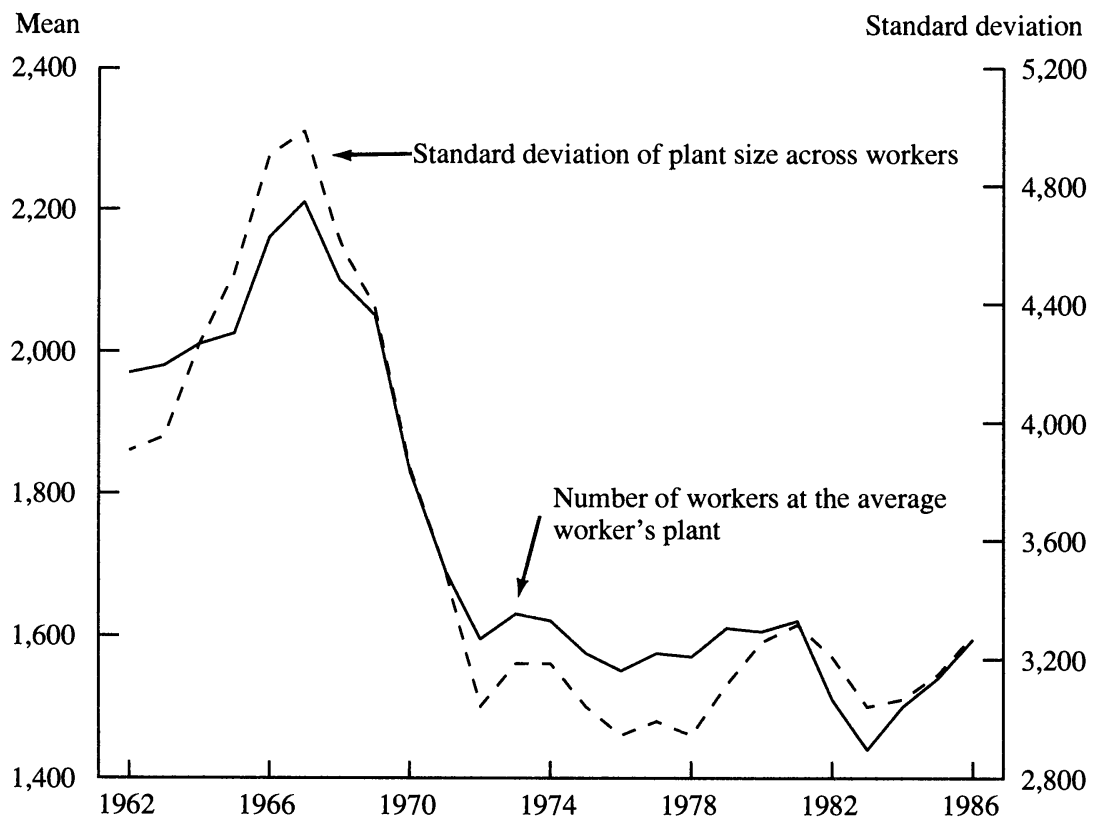

Source: Authors' estimates based on the Longitudinal Research Datafile and County Business Patterns Data.

workers at the average employee's workplace) and the standard deviation of plant size across workers. ${ }^{20}$ According to figure 4 .A, the coworker mean fell from 1,139 in 1967 to 665 in 1985, a striking 42 percent decline. The standard deviation of employer size across workers in the private sector fell by 45 percent over the same period. Figure 4.B shows that the pronounced shift toward smaller plants and greater uniformity in plant size across workers also occurred within the manufacturing sector. The coworker mean in the manufacturing sector fell

20. Davis (1990) describes the methodology for estimating these statistics. The coworker mean differs greatly from the establishment mean (average plant size) in terms of both its magnitude and time-series behavior. The coworker mean and associated higher moments of the distribution of workers by plant size are the appropriate measures to use when investigating labor market issues involving distributions across workers. See Davis and Haltiwanger (1989) and Davis (1990) for further discussion of this point. 
from 2,239 employees in 1967 to 1,587 employees in $1986 .{ }^{21}$ Coupled with the existing literature on the relationship between employer size and wages, these facts point to plant size as a potentially important factor in recent developments in the wage structure.

Another major structural change that occurred in the manufacturing sector is a shift toward more specialized plants. Gollop and Monohan construct generalized Herfindahl indexes of product diversification within manufacturing plants using census-year data in the LRD. ${ }^{22}$ They find increasing product specialization within manufacturing plants between 1967 and 1982, with sharper increases occurring among smaller plants. The shift toward more specialized plants over this period occurs in seventeen of twenty two-digit manufacturing industries. Using simpler measures, we present evidence that plant-level product specialization increased greatly between 1963 and 1986 in the manufacturing sector. The shift toward greater plant-level product specialization is a potentially important factor in explaining movements in wage dispersion within plants.

The manufacturing sector also experienced significant shifts in the occupational and skill mix of labor inputs in recent years. The top panel of table 1 shows large shifts away from operatives and toward managerial and professional workers since the mid-1970s. The middle panel shows dramatic shifts in the educational attainment of the manufacturing workforce. Workers with less than twelve years of schooling accounted for 40 percent of manufacturing hours between 1967 and 1969 but only 20 percent between 1985 and 1987. Over the same time span, the percentage of manufacturing hours accounted for by workers with at least some college rose from 20 percent to 37 percent. This shift toward

21. As figure 4B reveals, over 80 percent of this decline occurred from 1967 to 1972 . Preliminary investigation indicates that a large fraction of the 1967-72 decline is attributable to massive shrinkage of a few large plants in aerospace and defense industries as expenditures related to NASA and the Vietnam War fell sharply. After excluding these plants, the coworker mean still declines from 1967 to 1972 but at a much slower rate. (We thank Tim Dunne for this information.) In addition, Davis and Haltiwanger (1989) find that the shift away from large plants is widespread among two-digit manufacturing industries over this time period. Taken together, these observations suggest that the pronounced 1967-72 decline in the coworker mean reflects special factors in the aerospace and defense industries and other factors with a more widespread impact.

22. Gollop and Monahan (1989). Their generalization takes into account the distance between different SIC (standard industrial classification) products in the space of factor cost share vectors. 


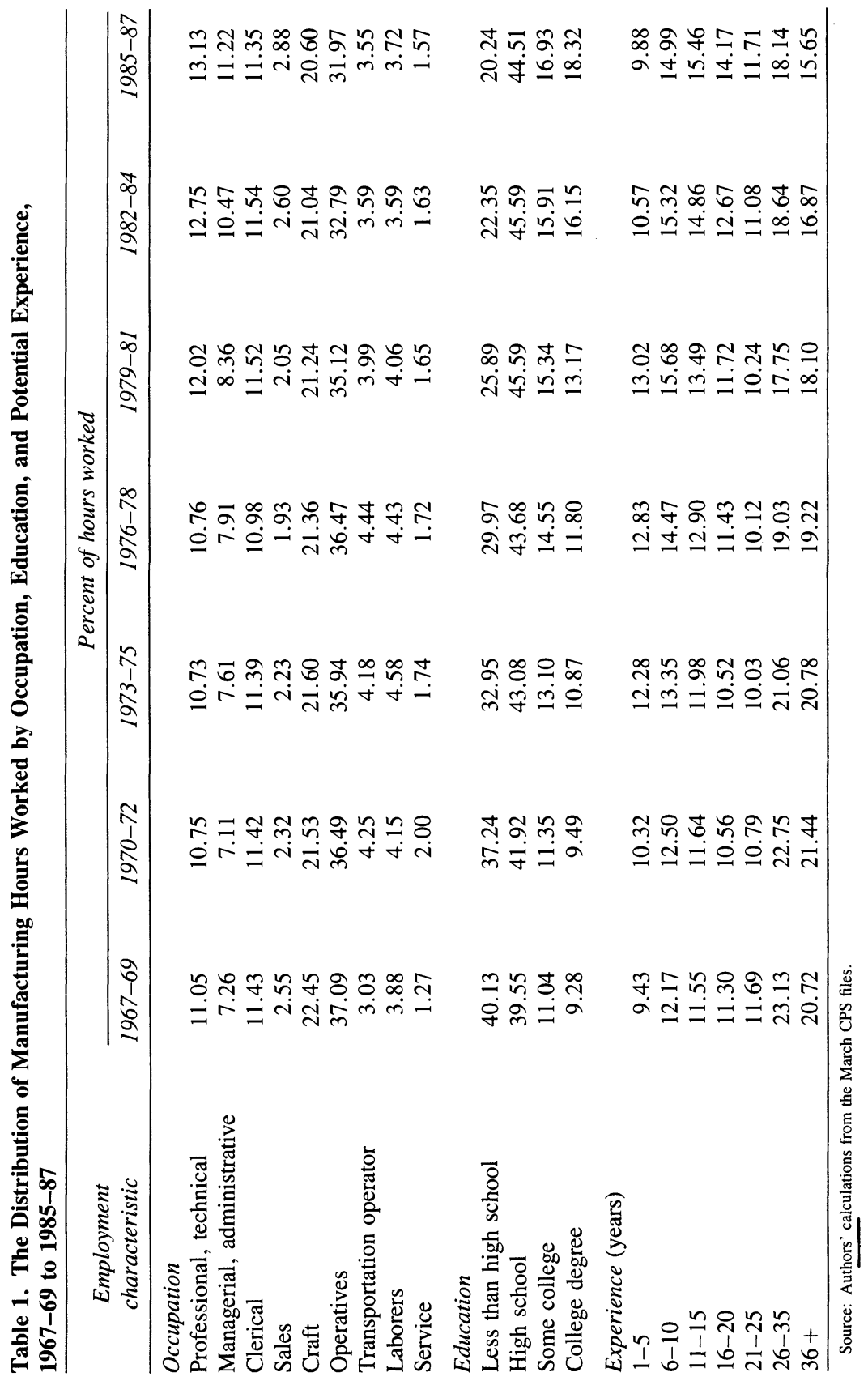


a more educated workforce in the manufacturing sector is much greater than the corresponding shift in the economy as a whole. In summary, table 1 shows pronounced increases in the skill intensity of manufacturing labor inputs since the late 1960s.

The preceding results document remarkable changes in the manufacturing workplace and work force during recent decades. Relative to the $1960 \mathrm{~s}$, the typical manufacturing workplace in the late $1980 \mathrm{~s}$ is more likely to be a small- or mid-sized plant, a specialized plant, and a nonunion plant. The typical manufacturing worker is more highly educated and more likely to engage in a nonproduction activity. In what follows, we examine the effects of these and other factors on the distribution of wages between and within manufacturing plants.

\section{Between-Plant and Within-Plant Components of Manufacturing Wage Dispersion}

In this section, we combine information from household and establishment surveys to decompose the variance of hourly manufacturing wages into between-industry, between-plant, and within-plant components for production and nonproduction workers. The decomposition quantifies the contribution of each component to the dispersion of manufacturing wages and to changes in wage dispersion over time.

\section{Decomposition Methodology}

The variance of hourly wages across hours worked in the manufacturing sector can be written as

$$
\begin{aligned}
V & =\alpha V^{p}+(1-\alpha) V^{n}+\alpha(1-\alpha)\left(\bar{W}^{p}-\bar{W}^{n}\right)^{2}, \\
& =\alpha\left(V_{B P}^{p}+V_{W P}^{p}\right)+(1-\alpha)\left(V_{B P}^{n}+V_{W P}^{n}\right) \\
& +\alpha(1-\alpha)\left(\bar{W}^{p}-\bar{W}^{n}\right)^{2},
\end{aligned}
$$

where $\alpha$ denotes production workers' share of hours worked, $V^{p}$ denotes the variance of wages across hours worked by production workers, $\bar{W}^{p}$ denotes the hours-weighted mean wage for production workers, $V_{B P}^{p}$ denotes the hours-weighted variance of mean production worker wages across plants, $V_{W P}^{p}$ denotes the hours-weighted mean of the pro- 
duction worker wage variances within plants, and the remaining terms denote analogous quantities for nonproduction workers. The first line of (1) expresses the total variance of hourly wages as the hours-weighted sum of within-worker-type and between-worker-type components. The second line further decomposes the within-worker-type components into between-plant and within-plant components. ${ }^{23}$

The between-plant and within-plant variance terms in (1) cannot be isolated from standard household surveys like the CPS, although the CPS does permit estimation of their sums, $V^{p}$ and $V^{n}$. To isolate the separate components of these sums, we first calculate $V_{B P}$ directly from wage data in the LRD. We then estimate the within-plant wage variance as a residual in a standard variance decomposition,

$$
\hat{V}_{W P}=V\left(W_{h}^{C}\right)-V_{B P},
$$

where $V\left(W_{h}^{C}\right)$ is the variance of measured wages in the CPS. To appreciate the assumptions implicit in this straightforward approach, it is

23. The decomposition of overall variation into between-plant and within-plant components is derived as follows. Temporarily suppressing superscripts for worker type, total variation in wages across hours worked (for a particular worker type) is given by:

$$
\begin{aligned}
\sum_{e} \sum_{h}\left(W_{e h}-\bar{W}\right)^{2} & =\sum_{e} \sum_{h}\left[\left(W_{e h}-W_{e}\right)+\left(W_{e}-\bar{W}\right)\right]^{2} \\
& =\sum_{e} \sum_{h}\left(W_{e h}-W_{e}\right)^{2}+\sum_{e} \sum_{h}\left(W_{e}-\bar{W}\right)^{2} \\
& =\sum_{e} H_{e} V_{e}+\sum_{e} H_{e}\left(W_{e}-\bar{W}\right)^{2}
\end{aligned}
$$

where $H=$ total hours worked, $H_{e}=$ hours worked at plant $e, W_{e h}=$ the wage for hour $h$ at plant $e, W_{e}=$ the mean hourly wage at plant $e$, and $V_{e}=$ the variance of wages across hours worked at plant $e$. Dividing through by $H$, and reintroducing superscripts for worker types, yields

$$
V^{p}=V_{B P}^{p}+V_{W P}^{p} \quad \text { and } \quad V^{n}=V_{B P}^{n}+V_{W P}^{n},
$$

where, for example,

$$
V_{W P}^{p_{W}}=\left(\frac{1}{H^{p}}\right) \sum_{e} H_{e}^{p} V_{e}^{p},
$$

and

$$
V_{B P}^{p}=\left(\frac{1}{H_{p}}\right) \sum_{e} H_{e}^{p}\left(W_{e}^{p}-\bar{W}^{p}\right)^{2}
$$


useful to consider the bias that results from measurement error in the CPS.

Let $W_{h}^{L}$ be the LRD wage for the $h$ th hour worked at the eth plant, and write this wage as

$$
\mathrm{W}_{h}^{L}=\boldsymbol{e}_{\boldsymbol{h}} \boldsymbol{W}_{\boldsymbol{e}}^{L}+\eta_{h},
$$

where $\mathbf{e}_{\mathbf{h}}$ is plant indicator vector, $\boldsymbol{W}_{\boldsymbol{e}}^{L}$ denotes the vector of hoursweighted mean plant wages, and $\eta_{h}$ denotes the deviation of the wage for the $h$ th hour worked about its mean plant wage. We observe the sector $\boldsymbol{W}_{\boldsymbol{e}}^{\boldsymbol{L}}$ in the LRD, but we do not observe $W_{h}^{L}$ for each hour worked. Assuming that mean plant wages are measured without error in the LRD, and computing variances on both sides of (3), we have

$$
V \equiv V\left(W_{h}^{L}\right)=V_{B P}+V_{W P},
$$

where $V_{B P}$ is calculated from plant-level observations in the LRD. ${ }^{24}$

Write the CPS wage observation for the $h$ th hour worked as the sum of the true (LRD) wage and measurement error,

$$
W_{h}^{C}=W_{h}^{L}+U_{h} .
$$

Computing variances on both sides of (5) and rearranging terms, we obtain an expression for the within-plant wage variance involving measured quantities and measurement error:

$$
V_{W P}=V\left(W_{h}^{C}\right)-V_{B P}-\left[V\left(U_{h}\right)+2 C\left(W_{h}^{L}, U_{h}\right)\right],
$$

where $V\left(U^{h}\right)$ is the variance of measurement error in the CPS wage observations, and $C\left(W_{h}^{L}, U_{h}\right)$ is the covariance between the true wage and the CPS measurement error.

Comparison of equations (6) and (2) makes clear that our use of $\hat{V}_{W P}$ to estimate the within-plant variance of wages relies on the identifying assumption that $\left[V\left(U_{h}\right)+2 C\left(W_{h}^{L}, U_{h}\right)\right]=0$. Testing this assumption requires both employer-reported and worker-reported wages for a sam-

24. The plant-level data in the LRD on employment, size, age, ownership type, and, for production workers, hours worked, and hourly wages are of high quality and relatively free of measurement error. Hence, we view the assumption of no measurement error in production worker hourly wages in the LRD as a reasonable basis for analysis. Measurement error in the LRD wages for nonproduction workers is much more severe for reasons discussed at length in the appendixes. 
ple of workers. Unfortunately, we know of no employer-worker matched data sets that correspond closely to the CPS and LRD in terms of sample design and execution and in terms of the compensation measure we use-hourly wages computed as annual salary and wages divided by annual hours worked. Appendix B reviews the available evidence on the structure of measurement error in household and establishment survey measures of wages. The appendix also reports estimates of the measurement error terms in (6) for a sample of six hundred manufacturing production workers drawn from a special supplement to the January 1977 CPS. The supplement contains employer-reported and workerreported observations on usual hourly earnings. Previous research and our analysis of the CPS supplement point to considerable mean reversion in the measurement error component of worker-reported wages. In other words, $C\left(W_{h}^{L}, U_{h}\right)<0$. This result indicates that the identifying assumption underlying (2) is consistent with available evidence. See appendix $\mathrm{B}$ for further discussion on this point.

Even if measurement error biases our estimate of the within-plant wage variance in any given year, it is unlikely to seriously distort our estimate of time-series changes in the within-plant variance of wages. A stable measurement error structure through time, as reflected in a relatively constant value of $\left[V\left(U_{h}\right)+2 C\left(W_{h}^{L}, U_{h}\right)\right]$, will lead to accurate estimates of the change in $V_{W P}$ under our methodology.

Returning to the variance decomposition in (1), we further decompose the between-plant components into between-industry $\left(V_{B I}\right)$ and between-plant, within-industry $\left(V_{B P I}\right)$ components to obtain

$$
\begin{aligned}
V=\alpha\left(V_{B I}^{p}+V_{B P I}^{p}+\right. & \left.V_{W P}^{p}\right)+(1-\alpha)\left(V_{B I}^{n}\right. \\
& \left.+V_{B P I}^{n}+V_{W P}^{n}\right)+\alpha(1-\alpha)\left(\bar{W}^{p}-\bar{W}^{n}\right)^{2}
\end{aligned}
$$

Equation (7) expresses overall manufacturing wage dispersion in terms of the wage gap between production and nonproduction workers and decompositions of production worker and nonproduction worker wage dispersion into between-industry, between-plant, and within-plant components. ${ }^{25}$

To estimate the components of (7), we proceed as follows. From the

25. By construction, $V_{B P}=V_{B P I}+V_{B I}$ for each worker type. 
individual-level wage observations in the CPS March files, we calculate $\alpha, \bar{W}^{p}$, and $\bar{W}^{n}$ for the manufacturing sector, and we calculate $V^{p}$ and $V^{n}$ for each two-digit manufacturing industry. From the plant-level wage observations in the LRD, we calculate $V_{B P}$ for each two-digit industry. Using (2), we then estimate $V_{W P}$ for each industry. Aggregating industry-level values (using LRD weights) yields the total manufacturing value of $V_{B P}$, and applying (2) once more yields the total manufacturing value of $V_{W P}$. Finally, we decompose $V_{B P}$ into its betweenindustry and within-industry components. In both the CPS and LRD, hourly wages are measured as annual salary and wages divided by annual hours worked. ${ }^{26}$ All calculations on individual, plant, and industry observations are carried out on an hours-weighted basis.

\section{Decomposition Results}

Table 2 reports the results of the decomposition exercise for selected years between 1975 and 1986 based on a breakdown of the manufacturing sector into twenty-two industries. According to line 2 of the table, the standard deviation of hourly manufacturing wages rose from $\$ 4.88$ in 1975 to $\$ 6.16$ in 1986 (1982 dollars). Lines 3-9 show measures of wage dispersion corresponding to each of the components in the variance decomposition in equation (7). Line 10 reports the fraction of hours accounted for by production workers. The bottom panel of table 2 shows the contribution of each component to the overall variance of manufacturing wages. Several results stand out.

First, 51 to 58 percent of the total variance in wages is accounted for by the dispersion in mean wages across plants. This figure is arrived at by summing the contributions of the $V_{B I}$ and $V_{B P I}$ terms in the bottom panel of table 2 (summing the contributions of lines $4,5,7$, and 8). The mean wage gap between production and nonproduction workers accounts for 6 to 9 percent of the total variance in wages. The remaining

26. For production workers, the LRD reports annual hours worked and the annual wage bill (exclusive of fringes and supplemental labor costs) for each plant. For nonproduction workers, the LRD reports only the annual wage bill and the number of employees in the mid-March payroll period during the year. To estimate $V_{B P}^{n}$, we combine information from the CPS and LRD to impute hours worked per nonproduction worker in each two-digit industry. Appendix A describes the imputation method. Appendix B discusses the bias in our estimates of $V_{B P}^{n}$ and $V_{W P}^{n}$ that potentially arises because of our inability to measure cross-plant variation in hours per nonproduction worker. 


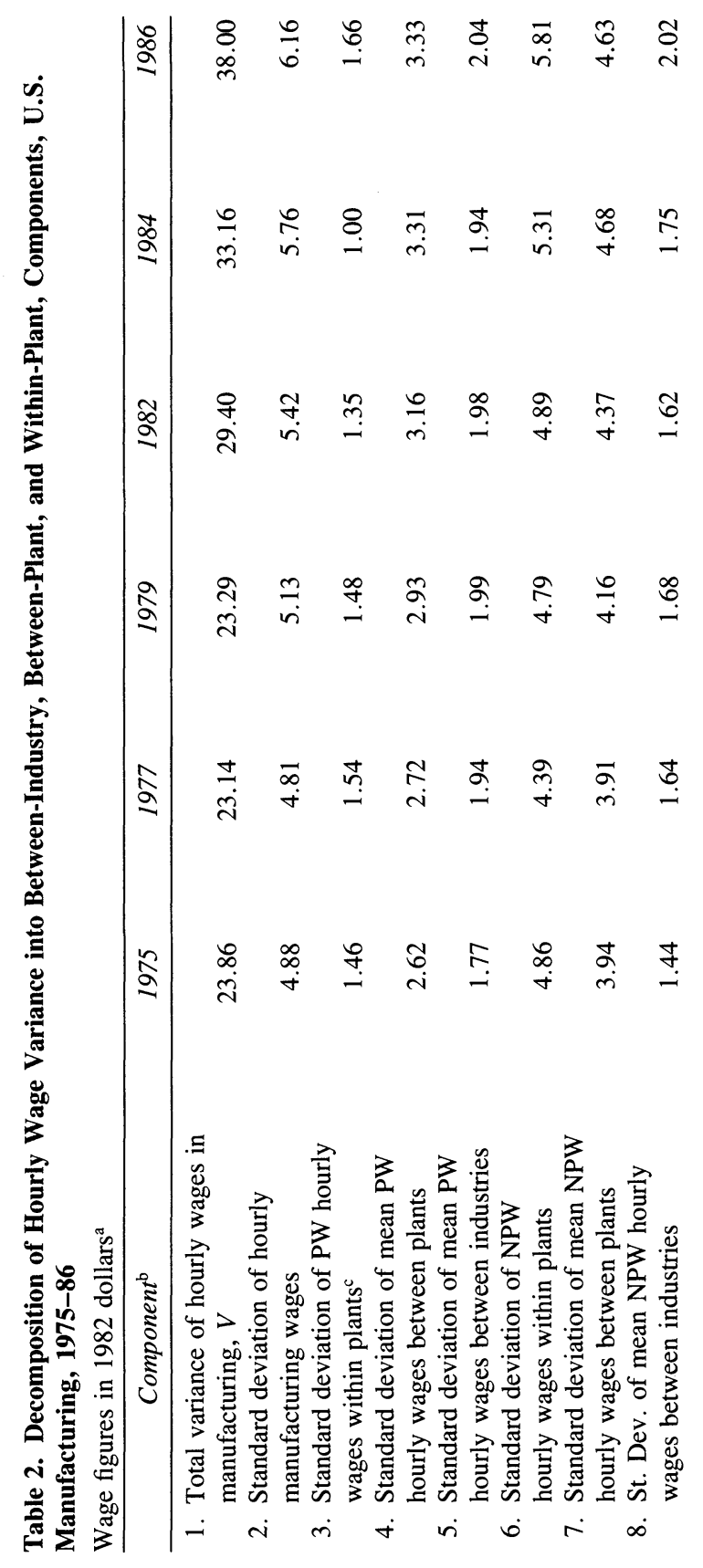




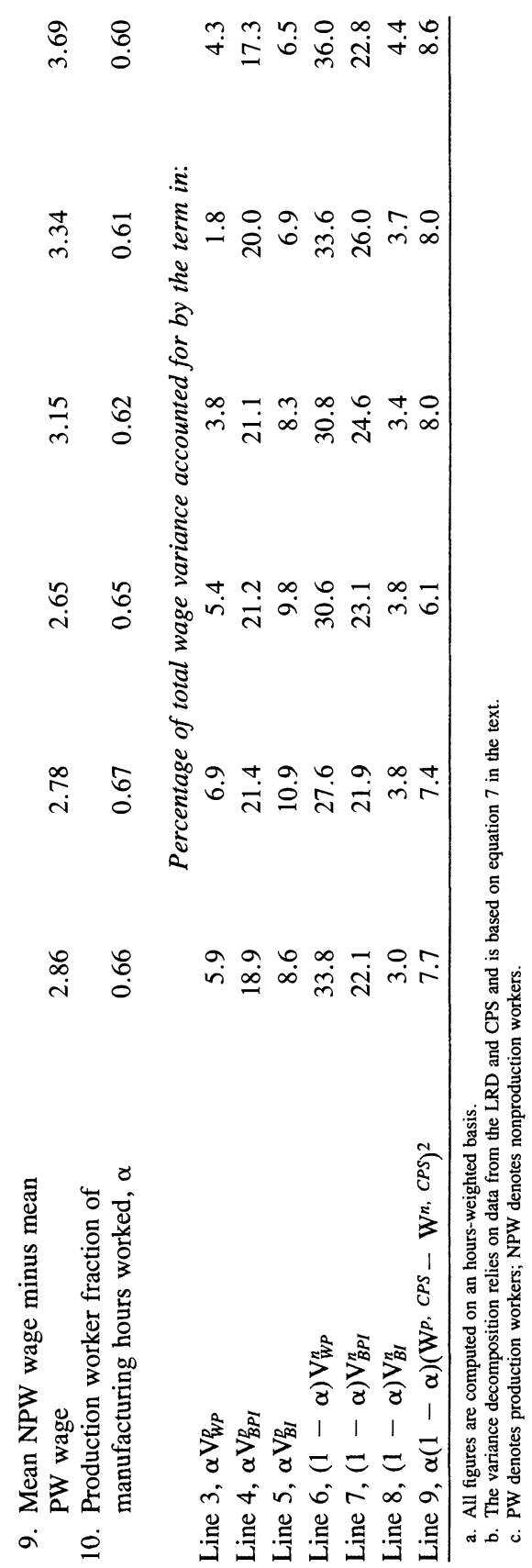


Table 3. Accounting for the 1975-86 Change in the Total Variance of Hourly Manufacturing Wages

Percent unless otherwise noted

With time-varying With $\alpha$ fixed at

Item

$\alpha$ its 1975 value

Wage variance change accounted for by:

Variance of PW wages within plants

1.7

14.6

3.0

39.7

24.0

6.7

10.2

19.6

4.9

24.6

14.4

4.9

8.6

Variance of mean NPW wages between industries
Wage gap between mean PW and mean NPW wages

1975-86 change in variance of hourly wages: 14.13

1975-86 change in the standard deviation of wages: 1.2

Source: See notes to table 2 .

source of wage variation in equation (7), the within-in plant variance of wages for each worker type, accounts for 35 to 40 percent of the total variance in wages.

Second, within-plant wage dispersion is much greater among nonproduction workers than production workers. The within-plant standard deviation of wages is roughly three to five times larger among nonproduction workers, depending on year. In addition, the between-plant standard deviation of wages within industries is 39 to 50 percent larger for nonproduction workers. A related point is that nonproduction workers account for a disproportionate fraction of overall wage dispersion. In 1986, for example, production workers account for 60 percent of hours worked in the manufacturing sector but only 28 percent of the overall wage variance, whereas nonproduction workers account for 63 percent of the overall variance.

Third, between-industry wage dispersion is of comparable magnitude for production and nonproduction workers, but the relative importance of the between-industry component differs greatly by worker type. Between-industry wage dispersion accounts for about one quarter of the overall variance in wages among production workers but never more than 7 percent of the overall variance among nonproduction workers. In this sense, almost all wage variation among manufacturing nonproduction workers occurs within two-digit industries.

Table 3 uses the figures in table 2 to calculate the contribution of 
each variance component to the rise in manufacturing wage dispersion between 1975 and 1986. The top panel in table 3 reports the change in each term of (7), divided by the change in the total variance. The bottom panel carries out a similar exercise, but it fixes the production worker share of hours worked at its 1975 value. Comparing the two panels provides information about the importance of the changing occupational distribution of manufacturing employment to the rise in manufacturing wage dispersion.

The top panel of table 3 indicates that each variance component in (7) accounts for part of the increase in overall wage dispersion. Between-plant components account for 48 percent of the growth in the wage variance, and within-plant components account for 41 percent. ${ }^{27}$ A rising wage gap between production and nonproduction workers accounts for the remaining growth in the overall wage variance.

Table 3 reveals sharply different patterns of wage inequality growth for production and nonproduction workers. Among nonproduction workers, most (56 percent) of wage inequality growth occurs within plants. In contrast, among production workers, within-plant wage dispersion accounts for a small ( 9 percent) fraction of wage inequality growth. Within-plant wage dispersion among production workers accounts for a minuscule 1.7 percent of the growth in the overall variance of wages between 1975 and 1986. Even with production workers' share of hours worked held constant at its 1975 value, within-plant wage dispersion among production workers accounts for only 3.0 percent of the growth in the variance of wages between 1975 and 1986.

The findings in tables 2 and 3 speak to at least three alternative views about the underlying causes of rising wage inequality in the United States. First, the results cast doubt on the view that rising wage inequality reflects the weakening of social norms or egalitarian forces that constrain the wage-setting process. To the extent that these constraints compress wage differentials at the workplace, one expects their relaxation to result in rising within-plant wage inequality among both production and nonproduction workers. While stories along this line that account for disproportionate wage inequality growth among nonproduction workers can undoubtedly be crafted, the virtual absence of

27. Between-plant components include between-industry and between-plant, withinindustry components for both production and nonproduction workers. 
rising within-plant wage inequality among production workers stands as an uncomfortable fact for this view.

Second, the results in table 3 cast doubt on the view that deunionization has been an important contributing factor to the growth of wage inequality in the manufacturing sector or in the economy as a whole. If unionism compresses the distribution of wages among production workers through standard rate compensation policies, as argued in the institutional literature, then we would expect the sharp recent decline in unionism to be associated with disproportionately large increases in wage dispersion among production workers. ${ }^{28}$ As table 3 makes clear, the facts are otherwise. While the results in table 3 do not rule out a role for deunionization in rising between-plant wage inequality or the rising wage gap between production and nonproduction workers, unionism-based stories are ill-suited to explaining the tremendous growth in wage dispersion among nonproduction workers or the rapid shift in employment toward nonproduction workers in the manufacturing sector. In short, the results in table 3 suggest that deunionization played at most a minor role in the growth of manufacturing wage dispersion between 1975 and 1986. Deunionization probably had even less impact on the structure of wages outside the manufacturing sector.

Third, the facts in tables 2 and 3 are consistent with the view that skill-biased technical change has been a major impetus behind the growth of wage inequality in the U.S. manufacturing sector. Hours worked by nonproduction workers rose from 33 percent of total manufacturing hours in 1977 to 40 percent in 1986. Over the same time span, the wage gap between nonproduction and production workers expanded by nearly one-third. Taken together, these two facts constitute strong prima facie evidence that the manufacturing sector experienced sharp increases in the relative demand for more highly skilled labor. This increase in the demand for more highly skilled labor could have been caused by skill-biased technical change that favors high-skill workers or by shifts in the composition of manufacturing product demand toward goods that intensively utilize high-skill labor inputs.

The bottom panel in table 3 provides additional evidence on the important role played by skill-biased technical change and/or product

28. Reynolds and Taft (1956); Slichter, Healy, and Livernash (1960); and Freeman (1980). 
demand shifts. Fixing $\alpha$ at its 1975 value and summing the contributions of the various components accounts for only 80 percent of the overall rise in the wage variance. The remaining 20 percent reflects the compositional shift from low-variance production workers to high-variance nonproduction workers. This finding suggests the following interpretation of rising wage inequality. Modes of production differ greatly in terms of the scope they offer for individual ability and skill differences to manifest as differences in productivity. At one extreme, assemblyline production processes require that all workers, from the most skilled to the least skilled, adhere to the line speed, thereby compressing the distribution of productivities (and wages) relative to the distribution of abilities. Other production processes have the character that each worker's productivity is affected multiplicatively by the ability of certain or all coworkers, thereby magnifying the distribution of productivities relative to the distribution of abilities. ${ }^{29}$ Production-worker intensive modes of production apparently offer less scope for ability and skill differentials to manifest as productivity differentials thar. nonproductionworker intensive modes. These remarks suggest that the portion of the wage variance increase not accounted for by the entries in the bottom panel of table 3,20 percent of the total increase, reflects a shift toward more ability-sensitive modes of production. The large contribution of within-plant wage dispersion among nonproduction workers, even with fixed $\alpha$, is also suggestive of a shift toward more abilitysensitive modes of production.

\section{Explanations for Wage Differences across Plants}

Why should wages differ greatly across employers within the same industry? Why should wages differ across workers within a plant? There are a host of candidate explanations for observed wage differentials and an enormous literature that seeks to evaluate the proposed explanations. See, for example, the list of potential explanations and the related

29. Miller (1982) and Rosen (1982) develop hierarchical models of the firm in which each worker's ability multiplicatively affects the productivity of all subordinates to the worker. 
literature surveyed in Katz and Summers. ${ }^{30}$ In our discussion, we focus on the implications of alternative explanations for the between-plant and within-plant distribution of wages and for time-series changes in these distributions.

\section{Competitive Explanations}

Technological heterogeneity across plants within the same industry arises for many reasons. The anticipated scale and variablity of future production, as well as the probability distribution over future factor prices, vary across locations and over time. Available production technologies also vary over time. These considerations influence the firm's choice of production technology when it constructs a new plant or reinvests in an old plant. Given that the choice of production technology and plant location entails significant sunk costs, these time- and location-specific differences in initial conditions generate persistent heterogeneity in production techniques among operating plants. Lambson shows that even when competitive firms face identical initial conditions and have identical information sets, they may choose different production technologies. Lucas and Oi develop models in which firm heterogeneity arises from heterogeneity in entrepreneurial ability. ${ }^{31}$

These and other sources of technological heterogeneity among plants induce sorting by worker ability, which in turn leads to between-plant wage dispersion within industries. ${ }^{32}$ This sorting takes many forms. Hamermesh suggests that larger plants use higher-quality workers more intensively because of greater capital intensity at large plants and complementarities between physical capital and the worker's skill. ${ }^{33} \mathrm{Al}$ ternatively, Oi argues that large plants employ higher-quality workers

30. Katz and Summers (1989).

31. Lambson (1991); Lucas (1978); and Oi (1983). Time- and location-specific differences in initial conditions are likely to generate significant heterogeneity in the choice of technology across firms and across plants within firms. Similarly, differences in entrepreneurial ability are likely to generate differences across firms and across plants within firms. While it would be useful to separate between-plant dispersion into distinct between-firm and within-firm components, we do not undertake that task here.

32. Technological heterogeneity in a competitive environment can also generate differences in working conditions across plants, leading to between-plant wage dispersion associated with compensating wage differentials. See Rosen (1986).

33. Hamermesh (1980). 
to reduce monitoring costs per unit of labor services. ${ }^{34}$ Clearly, both of these sorting mechanisms generate a positive, skill-based relationship between wages and employer size. Oi also argues that firm-specific human capital accumulation occurs primarily at large firms and plants. If higher-quality workers have an advantage in accumulating firmspecific skills, then the dynamics of specific human capital accumulation provide another sorting mechanism that generates a positive, skill-based relationship between wages and employer size. In addition, many forms of skill complementarities across workers lead to ability sorting across plants. Oi, for example, argues that large plants often operate with technologies that rely heavily on standardization and teamwork and therefore require homogeneous, high-quality work forces. Finally, plants of different ages will exhibit differences in their work-force distributions over tenure and experience, which in turn generate plant-wage differentials in theories of human capital, job shopping, and employerworker matching.

Within-plant wage dispersion is tied to these technological differences among plants as well. To the extent that plants use a mix of skill types, within-plant wage dispersion naturally arises. The degree of within-plant dispersion is likely to vary systematically by plant type. For example, if large plants require a more homogenous type of production worker, then within-plant dispersion among production workers will be smaller at larger plants.

A simple supply and demand framework helps illustrate the role of competitive influences on the between-plant and within-plant structure of wages. In what follows, we focus on skill differentials, but job attribute differentials could be characterized in a similar fashion.

Suppose there are $J$ types of labor skills and $K$ types of plants. Without loss of generality, normalize the number of plants of each type to be 1 . It is easily shown that the equilibrium wage and hours for skill type $j$ can be represented as

$$
\begin{gathered}
h_{j}=\sum_{k} h_{j k}(\boldsymbol{\theta}, \boldsymbol{\alpha}) \quad \text { and } \\
w_{j}=w_{j}(\boldsymbol{\theta}, \boldsymbol{\alpha}),
\end{gathered}
$$

where $h_{j k}$ is the hours for skill $j$ at plant $k, w_{j}$ is the wage for skill $j, \boldsymbol{\theta}$ 
is a vector of plant-level demand shifters, and $\boldsymbol{\alpha}$ is a vector of supply shifters for skill types.

The equilibrium mean wage at plants of type $k$ is given by

$$
w_{k}=\sum_{k}\left(\frac{h_{j k}(\boldsymbol{\theta}, \boldsymbol{\alpha})}{h_{k}(\boldsymbol{\theta}, \boldsymbol{\alpha})}\right) w_{j}(\boldsymbol{\theta}, \boldsymbol{\alpha}),
$$

where $h_{k}$ is the total quantity of hours demanded by plants of type $k$. The total variance in wages across hours worked is easily decomposed into between- and within-plant components:

$$
V=V_{B P}+V_{W P}
$$

where

$$
V_{B P}=\sum_{k}\left(\frac{h_{k}(\boldsymbol{\theta}, \boldsymbol{\alpha})}{h(\boldsymbol{\theta}, \boldsymbol{\alpha})}\right)\left(w_{k}(\boldsymbol{\theta}, \boldsymbol{\alpha})-\bar{w}(\boldsymbol{\theta}, \boldsymbol{\alpha})\right)^{2},
$$

and

$$
V_{W P}=\sum_{k}\left(\frac{h_{k}(\boldsymbol{\theta}, \boldsymbol{\alpha})}{h(\boldsymbol{\theta}, \boldsymbol{\alpha})}\right) \sum_{j}\left(w_{j k}(\boldsymbol{\theta}, \boldsymbol{\alpha})-w_{k}(\boldsymbol{\theta}, \boldsymbol{\alpha})\right)^{2}
$$

This representation makes clear that changes in demand and supply conditions affect between-plant and within-plant wage dispersion through a number of channels. Changes in demand and supply conditions affect the wage distribution for skill types, thereby affecting both within-plant and between-plant wage dispersion for a fixed distribution of skill types. Further, changes in demand and supply conditions alter the distribution of skill types between and within plants, thereby altering between-plant and within-plant wage dispersion.

A special case of this framework helps interpret some of the subsequent empirical findings. Suppose there are two skill types (high and low) and two plant types (large and small). Suppose technologies are such that only large plants can take advantage of the difference in skills. Consider an equilibrium in which initially all high-skill labor is employed at large plants, high-skill labor earns a higher wage than lowskill labor, large plants employ both skill types, and small plants employ only low-skill labor.

Within the context of this special case, consider two distinct types of labor demand disturbances. First, consider a skill-biased technology 
shock that increases the difference between the productivity of highand low-skill labor at large plants. For example, we suggested in the introduction that the spread of computer technology and greater reliance on more flexible production techniques are factors that have perhaps increased the relative demand for more skilled workers. ${ }^{35}$

Skill-biased technical change of this sort increases the demand for high skilled labor and (assuming substitution effects dominate) reduces the demand for low skilled labor at large plants. While the effect on total employment at large plants is ambiguous, average labor quality at large plants rises. Wages for high-skill labor rise, and wages for lowskill labor fall. Wages at small plants fall, and (with reasonable assumptions about supply and demand elasticities) wages at large plants rise because of the rising wage for high-skill labor and an increase in work-force quality at large plants. Overall then, this skill-biased technology shock induces a reallocation of low-skill labor to small plants and an increase in both the size-wage differential and the skill-wage differential. While this technology shock induces a reallocation of lowskill workers toward small plants, the impact on the distribution of total employees by plant size is ambiguous. ${ }^{36}$

This technology shock affects overall wage dispersion through several channels. The increase in the employer size-wage differential tends to increase between-plant wage dispersion. The increase in the skillwage differential tends to increase within-plant wage dispersion at large

35. Case studies reported by Bailey $(1989,1990)$ provide direct evidence that the spread of computer technology and more flexible production techniques have influenced the demand for more skilled workers in this manner. For example, on the basis of his case studies of plants in textiles and apparel industries he states that "the increasing need for technical skills is particularly acute among repair and maintenance personnel." This need resulted from factors like the installation of "state-of-the-art air-jet looms" and the expansion of the number of "weaves and colors" produced. See Bailey (1990, p. 24). Other types of workers have been similarly affected. For example, "Even the loom cleaners, who are among the lowest paid workers in the plant, now must at least be able to read instructions and punch numbers into a key pad.' Bailey (1990, p. 25).

36. Note that a very different type of skill-biased technical change can produce similar results. Suppose high- and low-skill workers are strong complements in the production process at large plants and suppose further that high- and low-skill labor are inelastically supplied. Then a technology shock that raises the productivity of low-skill workers relative to high-skill workers can generate an increase in the skill differential; an increase in the employer size differential; and the reallocation of low-skill workers from large to small plants. 
plants. ${ }^{37}$ Compositional effects from the reallocation of low-skill labor to small plants and the increased use of high-skill labor at large plants also affect between- and within-plant dispersion.

Alternatively, consider a shift in relative product demands that reduces demand for the products produced by large plants. This case is of interest given increased foreign competition for products produced by large plants in the United States (for example, in auto and steel). ${ }^{38}$ This product demand shift reduces demand for both high- and low-skill labor at large plants, and total employment at large plants falls. Again, some low-skill labor is reallocated from large to small plants. For reasonable supply elasticities, the skill differential falls since the demand for high-skill labor (which derives entirely from large plants) falls disproportionately relative to the fall in demand for low-skill labor (which derives from both large and small plants). The impact of this decrease in the skill-wage differential on the size-wage differential is ambiguous. For fixed-skill shares at large plants, the decrease in the skill-wage differential decreases the size-wage differential. However, the decrease in the skill-wage differential induces an increased reliance on high-skill labor at large plants. This substitution response increases the size-wage differential. If these substitution effects are weak, then the first effect dominates. Overall, this product demand shift induces a reallocation of low-skill labor toward small plants, a decrease in the skill-wage differential, and an ambiguous change in the size-wage differential. In addition to the shift in the size distribution of low-skill labor, there is a shift in the size distribution of total employment toward small plants.

This product demand shift also affects overall wage dispersion through both between-plant and within-plant effects. The decrease in the skillwage differential acts to decrease within-plant dispersion. If the sizewage differential falls as well, between-plant dispersion declines. Composition effects from the reallocation of low-skill labor to small plants and the increased use of high-skill labor at large plants also affect between-plant and within-plant wage dispersion.

37. Our example has the obvious limitation that it does not incorporate factors that generate within-plant wage dispersion at small plants.

38. Changing trade patterns can influence the wage and employment structure through channels other than simple shifts in relative product demand across plants. We return to this matter in the conclusion. 
We will return to these two examples of labor demand disturbances later in this paper. There, the evidence we develop on time-series changes in size-wage differentials and changes in the distribution of hours worked by plant size will help us to discriminate between explanations for rising wage inequality based on biased technical change and explanations based on relative product demand shifts.

\section{Noncompetitive and Institutional Explanations}

Now let us turn to noncompetitive and institutional factors that influence wage dispersion between and within plants. These noncompetitive explanations have been discussed extensively in research on interindustry wage differentials. ${ }^{39}$ Many explanations for interindustry wage differentials are based on the idea that the nature of the employeremployee relationship differs systematically across industries. These same arguments can be applied to argue that the nature of the employeremployee relationship differs systematically across plants within industries. For example, monitoring technologies can vary both across and within industries. If monitoring is imperfect and more difficult at large plants, then employer size-wage differentials can emerge following standard efficiency wage arguments.

Wage dispersion across industries or plants can also reflect differences in rent sharing. Rents can arise when employers have product market power or when employers have cost differentials with respect to nonlabor inputs. If wages are partly determined by rent-sharing considerations, then cross-plant differences in rents or in worker ability to extract rents would generate between-plant wage dispersion.

While these noncompetitive factors can account for cross-sectional dispersion, it is less clear that they yield additional and plausible explanations for time-series changes in the distribution of wages. Consider, for example, an efficiency-wage explanation for between-plant wage dispersion. In the absence of standard demand or supply disturbances, a time-series increase in between-plant dispersion could be generated by changes in the monitoring technology that make it relatively more difficult to monitor workers at large plants. As an explanation for major shifts in the wage structure, this line of argument

39. Katz and Summers (1989). 
seems farfetched. More plausibly, these noncompetitive factors might influence the response to standard demand and supply disturbances that affect wage dispersion.

Consider briefly how a product demand shift might interact with a noncompetitive explanation of cross-sectional dispersion. Suppose that the size-wage differential is due to efficiency wages in the manner discussed above, and consider a product demand shift that reduces the demand for products at large plants relative to those at small plants. This disturbance induces a reallocation of labor away from large plants toward small plants, and wages at both types of plants fall. The impact on the size-wage differential depends on the relative demand and supply elasticities. For sufficiently elastic demand at small plants, the sizewage differential falls. ${ }^{40}$ Overall, then, the effects of a product demand shift in this noncompetitive environment are similar to the effects in the competitive model discussed above. (However, there are no skillcomposition effects influencing the wage response at large plants in this noncompetitive example.) Thus, regardless of whether between-plant wage dispersion is generated by ability sorting or efficiency-wage considerations, a reduction in the demand for products produced by large, high-wage plants induces a reallocation of low-skill labor toward small, low-wage plants. Under plausible auxiliary assumptions, the demand shift also causes a decline in the size-wage differential in both models.

Finally, unions clearly seek to influence the between-plant and withinplant structure of wages, and unionism often figures prominently in noncompetitive explanations for wage differentials. The well-documented union wage gap is associated with wage differentials between plants and between worker types. Freeman argues that, on net, unionism compresses wage differentials across workers. In light of these considerations, one might suspect that the large recent declines in union density are an important factor contributing to rising wage dispersion in the manufacturing sector. ${ }^{41}$ But, as we argued previously, the evidence presented in table 3 supports the view that unionism-based factors played little role in rising wage dispersion. Below, we present additional evidence that supports this view.

40. We have in mind an upward-sloping, no-shirking condition in the efficiency-wage sector.

41. Freeman $(1980,1982)$. 


\section{The Role of Observable Plant Characteristics}

In this section, we investigate the role of observable plant characteristics in the distribution of wages across plants. We focus on three questions. What are the basic patterns of variation that link observable plant characteristics to plant wages? How much of the between-plant dispersion of wages is accounted for by observable plant characteristics? What information do time-series changes in the plant-wage structure provide about the underlying driving forces behind rising wage inequality? The observable plant characteristics we consider are industry, size, age, region, ownership type (single- or multiunit), energy intensity, capital intensity, and product diversification. Our reported results place relatively little emphasis on wage differentials by industry and region, since they have been studied at length in research based on household surveys, and since we have already quantified the contribution of industry effects in tables 2 and 3 .

\section{Wage Differentials and Hours Worked by Plant Type}

Table 4 reports wage differentials and between-plant standard deviations by plant type for production and nonproduction workers. Wage differentials by plant type for a given year are defined as the difference between the mean wage for the plant type and the overall mean wage for the given year. All figures are in 1982 dollars. The table reports time-series averages as well as the 1963-86 change. ${ }^{42}$

Mean wages are higher at larger plants, older plants, multiunit plants, more energy intensive plants, more specialized plants, and more capital intensive plants. The most striking differentials involve plant size. The average wage gap between plants with more than 5,000 employees and plants with 20 to 49 employees is $\$ 4.92$ per hour for production workers and $\$ 3.60$ per hour for nonproduction workers. These size-wage gaps are quite large relative to the average wage of $\$ 8.56$ for production workers and $\$ 12.96$ for nonproduction workers.

Large size-wage gaps occur within detailed manufacturing industries as well. In unreported results, we recomputed the wage differentials in

42. We do not report time-series changes for our capital intensity classes given the way these classes are constructed. See appendix A for details. 
Table 4. Wage Differentials and Between-Plant Dispersion by Observable Plant Characteristics

Wages are in 1982 dollars

\begin{tabular}{cccccccc}
\hline & \multicolumn{3}{c}{ Production workers } & & \multicolumn{3}{c}{ Nonproduction workers } \\
\cline { 2 - 3 } Plant & Mean & Between- & & Mean & Between- & \\
characteristics & wage & plant & Fraction & & wage & plant & Fraction \\
differen- & standard & of hours & & differen- & standard & of hours \\
tial & deviation & worked & tial & deviation & worked \\
\hline
\end{tabular}

Time-series averages $^{\mathrm{a}}$

Size

$\begin{array}{lrrrrrr}1-19 \text { employees } & -1.08 & 3.16 & 0.06 & -1.92 & 5.99 & 0.05 \\ 20-49 & -1.27 & 2.91 & 0.09 & -0.89 & 6.37 & 0.08 \\ 50-99 & -1.35 & 2.73 & 0.10 & -0.77 & 5.74 & 0.09 \\ 100-249 & -1.15 & 2.63 & 0.18 & -0.93 & 4.84 & 0.16 \\ 250-499 & -0.84 & 2.70 & 0.16 & -0.85 & 4.24 & 0.14 \\ 500-999 & -0.01 & 2.86 & 0.14 & -0.42 & 3.78 & 0.13 \\ 1,000-2,499 & 1.41 & 2.94 & 0.12 & 0.43 & 3.61 & 0.14 \\ 2,500-4,999 & 3.18 & 2.59 & 0.07 & 1.65 & 3.51 & 0.09 \\ 5,000+ & 3.65 & 2.19 & 0.08 & 2.71 & 2.65 & 0.13 \\ \text { Age } & & & & & & \\ 0-4 \text { years } & -1.19 & 3.19 & 0.12 & -0.78 & 4.92 & 0.11 \\ 5-9 & -1.26 & 3.05 & 0.12 & -0.78 & 5.14 & 0.12 \\ 10+ & 0.45 & 3.52 & 0.75 & 0.26 & 4.64 & 0.77\end{array}$

Ownership type

Single plant

$\begin{array}{rr}-1.46 & 2.84 \\ 0.53 & 3.15\end{array}$

$0.27-0.81$

6.07

0.21

Multi-plant

0.53

0.73

4.12

0.79

Energy Cost as \%

of sales

Less than $1 \%$

$1 \%$ to $5 \%$

$\begin{array}{ll}-0.15 & 3.26\end{array}$

0.45

0.22

0.46

0.07

4.72

0.53

$-0.13 \quad 3.08$

$-0.25$

4.53

0.40

More than 5\%

$1.24 \quad 3.14$

0.09

0.44

4.26

0.07

Product

specialization $^{\mathrm{b}}$

Specialized

1st quartile

$\begin{array}{rr}-1.05 & 2.98 \\ 0.40 & 3.06 \\ 0.48 & 3.12 \\ 0.73 & 3.22 \\ 1.17 & 3.21\end{array}$

0.39

$-0.56$

5.43

0.31

2d quartile

$3 \mathrm{~d}$ quartile

4th quartile

1.17

0.16

0.23

4.40

0.14

$0.15-0.14$

4.23

0.18

0.16

0.33

4.34

0.19

0.14

0.79

4.05

0.18

Capital intensity ${ }^{\mathrm{c}}$

1st quintile

$2 \mathrm{~d}$ quintile

$3 d$ quintile

4th quintile

5 th quintile

$\begin{array}{rr}-2.43 & 2.74 \\ -1.00 & 2.90 \\ -0.05 & 2.98 \\ 0.84 & 3.18 \\ 2.63 & 3.40\end{array}$

0.20

$-1.77$

5.23

0.15

0.20

$-0.81$

4.61

0.21

0.20

$-0.18$

4.42

0.22

0.20

0.59

4.54

0.21

0.20

1.76

4.51

0.20 
Table 4. (continued)

\begin{tabular}{cccccccc}
\hline & \multicolumn{3}{c}{ Production workers } & & \multicolumn{3}{c}{ Nonproduction workers } \\
\cline { 2 - 3 } & Mean & Between- & & & Mean & Between- & \\
Plant & wage & plant & Fraction & wage & plant & Fraction \\
characteristics & differen- & standard & of hours & differen- & standard & of hours \\
& tial & deviation & worked & tial & deviation & worked \\
\hline
\end{tabular}

1963-86 changes

Size

1-19 employees

0.06
-0.56
-0.60
-0.51
-0.28
0.02
0.99
2.21
2.22

0.97

0.53

20-49

50-99

100-249

250-499

500-999

1,000-2,499

2,500-4,999

$5,000+$

Age (1972-86

change)

$0-4$ years

5-9

$10+$

Ownership type

Single plant

Multi-plant

Energy costs as \%

of sales

Less than $1 \%$

$1 \%$ to $5 \%$

More than 5\%

$\begin{array}{rr}0.02 & 1.31 \\ -0.18 & 1.19 \\ 0.26 & 1.62\end{array}$

0.73

1.45

$-0.10$

0.10

-0.02
0.01
0.02
0.04
0.02
0.00
-0.02
-0.01
-0.02

\subsection{7}

1.04

$-0.03$

$-0.32$

0.73

0.00

$-0.88$

0.01

$-0.76$

0.19

0.02

$-0.63$

0.48

0.01

$-0.02$

0.45

0.00

0.21

0.72

$-0.01$

1.35

1.10

0.83

$-0.01$

1.21

1.10

0.00

-0.13
0.03
0.10

0.62
-0.52
-0.07

$-0.74$

$-0.11$

$-0.08$

0.03

0.81

0.08
$-0.43$

0.81

$-0.09$

$-0.02$

1.05

0.09
0.70

$-0.22$

0.24
0.19

0.00

0.96

0.19

0.06

0.21

1.06

0.03

Product

specialization $^{b}$

Specialized

1st quartile

0.38

1.16

0.31

0.12

$-0.05$

0.30

2d quartile

0.59

1.25

$-0.05$

0.68

$3 d$ quartile

0.41

1.27

$-0.06$

$-0.01$

0.84

$-0.02$

0.85

1.46

$-0.08$

0.82

$-0.04$

0.83

1.61

0.51

0.97

$-0.11$

$-0.12$

1.17

1.06

$-0.14$

a. Time-series averages are based on 1963, 1967, 1972, 1977, 1982, and 1986 observations except for age values, which exclude 1963 and 1967. All statistics are computed on an hours-weighted basis.

b. The product-specialization ratio equals the fraction of plant shipments accounted for by the primary five-digit product class. Completely specialized denotes plants with a ratio of one. The other rows report figures by pooled-sample quartiles of the product specialization ratio for nonspecialized plants. The pooled-sample quartile values are $0.53,0.72$, and 0.90 .

c. Capital intensity is defined as the ratio of book value of capital to total employment. Reported statistics by capital intensity quintiles were constructed for each birth cohort-year cell and then averaged across cells. 
table 4 while controlling for twenty-two two-digit industry effects in each year. These size-wage differentials exhibit the same pattern as the raw differentials, although the magnitudes are muted. When we control for two-digit industry effects, the mean production worker wage gap between plants with more than 5,000 employees and plants with 20 to 49 employees is $\$ 2.82$ per hour. Controlling for two-digit industry effects reduces the standard deviation of the mean wage differentials across size classes by 39 percent.

Table 4 also shows considerable cross-plant wage dispersion within size, age, ownership type, energy share, product specialization, and capital intensity classes. For production workers, between-plant wage dispersion displays a modest tendency to fall as plant size increases. This tendency is somewhat more pronounced when we control for twodigit industry effects. For nonproduction workers, the inverse relationship between plant size and between-plant wage dispersion is much sharper and nearly monotonic. Although mean nonproduction worker wages rise sharply with plant size, between-plant wage dispersion falls from $\$ 6.37$ per hour at plants with 20 to 49 employees to $\$ 2.65$ per hour at plants with more than 5,000 employees. These results point to much greater heterogeneity in average work-force quality among small manufacturing plants than among large manufacturing plants, especially with respect to nonproduction workers.

The distribution of hours worked by plant types reveals several clear patterns. There is a greater concentration of nonproduction worker hours at large plants. On average, 36 percent of nonproduction worker hours, but only 27 percent of production worker hours, are worked at plants with more than 1,000 employees. Perhaps the most striking aspect of the hours distribution is the large fraction of hours worked at older and multiunit plants. The fraction of hours worked at plants that produce a single five-digit SIC product is also quite large. ${ }^{43}$

Turning to time-series changes in the plant-wage structure, we find that wage differentials by age, ownership type, energy intensity, and product specialization exhibit modest changes over the sample period. Size-wage differentials exhibit dramatic increases. For production workers, the hourly wage gap between plants with 20 to 49 employees

43. The Standard Industrial Classification system contains roughly 1,300 five-digit product classes for manufactured goods. 
and plants with more than 5,000 employees rose by $\$ 2.78$. For nonproduction workers, the equivalent size-wage gap rose by $\$ 1.53$.

Between-plant wage dispersion grew for all plant classifications for production workers and for virtually all classifications for nonproduction workers. Greater increases occurred among larger plants, multiunit plants, young plants, and less specialized plants. The reported statistics also show substantial increased in the fraction of hours worked at smaller plants, older plants, multiunit plants, plants with higher energy costs, and a dramatic increase in the fraction of hours accounted for by more specialized plants. Note that the shift away from hours worked at large plants is more pronounced for production workers than for nonproduction workers.

\section{Between-Type and Within-Type Components of Wage Dispersion among Plants}

The basic tabulations of wages by plant type point to systematic relationships between plant characteristics and wages. To help gauge the magnitude of these relationships, table 5 decomposes the total between-plant variance of wages into between and within components for various observable plant characteristics. ${ }^{44}$ Taken individually, the between-type contributions to total between-plant wage variation are modest for most characteristics, typically accounting for 8 percent or less. Wage variation by plant size is the exception, accounting for 26 percent of between-plant variation among production workers and 9 percent among nonproduction workers. ${ }^{45}$

Turning to time-series changes in between-plant wage dispersion, we find that a parallel story emerges. Most of the observable characteristics, taken individually, account for modest amounts (often less than 5 percent) of the 1963-86 increase in between-plant wage dis-

44. Table 5 is based on the categories used in table 4: nine size classes, three age classes, two ownership types, three energy cost share classes, and five product specialization categories.

45. In multivariate cross-sectional regressions of plant wages on a quartic in size, nine regions, three energy cost classes, two ownership types, five product specialization classes, 22 two-digit industries and no interaction terms, the observable plant characteristics account for about one-half of total between-plant wage variation. For production workers, the time series of $R^{2}$ values is 0.48 (1963), 0.47 (1967), 0.50 (1972), 0.54 (1977), 0.48 (1982), and 0.46 (1986). Adding three age classes to the 1986 regression increases the $R^{2}$ to 0.48 . 


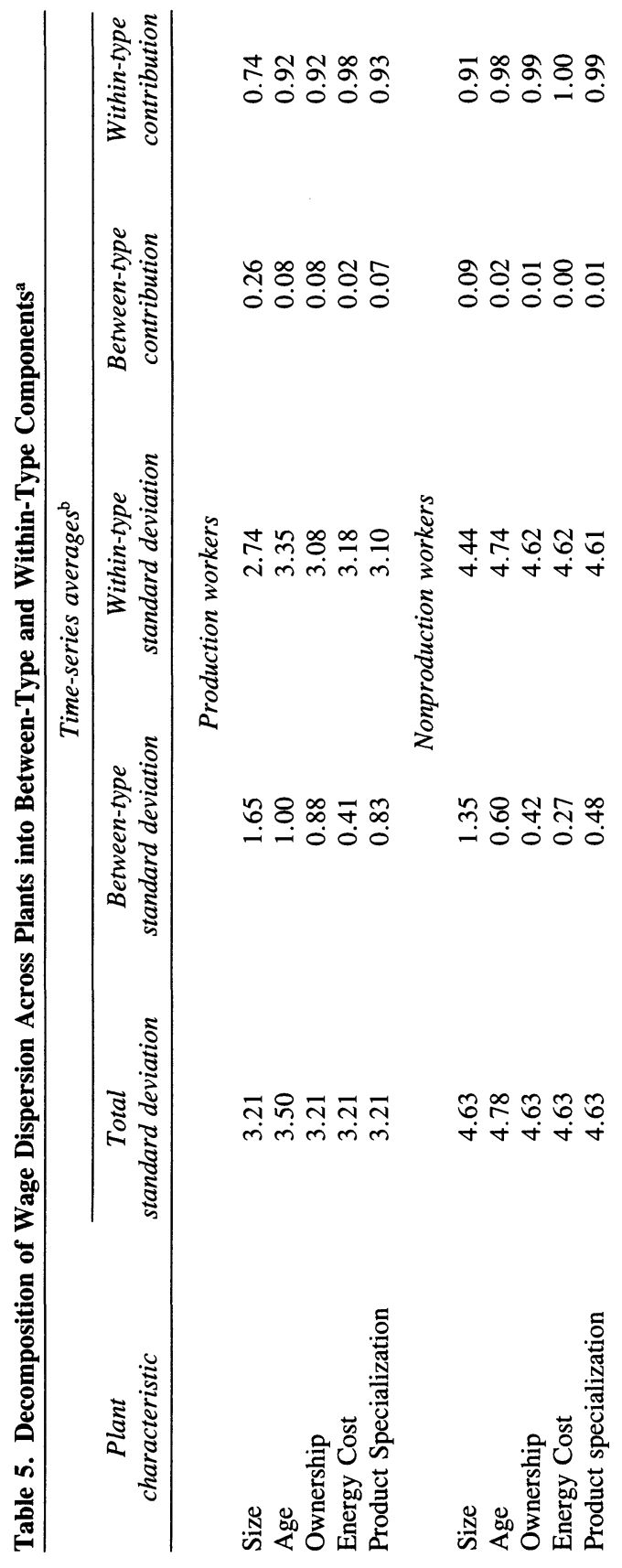




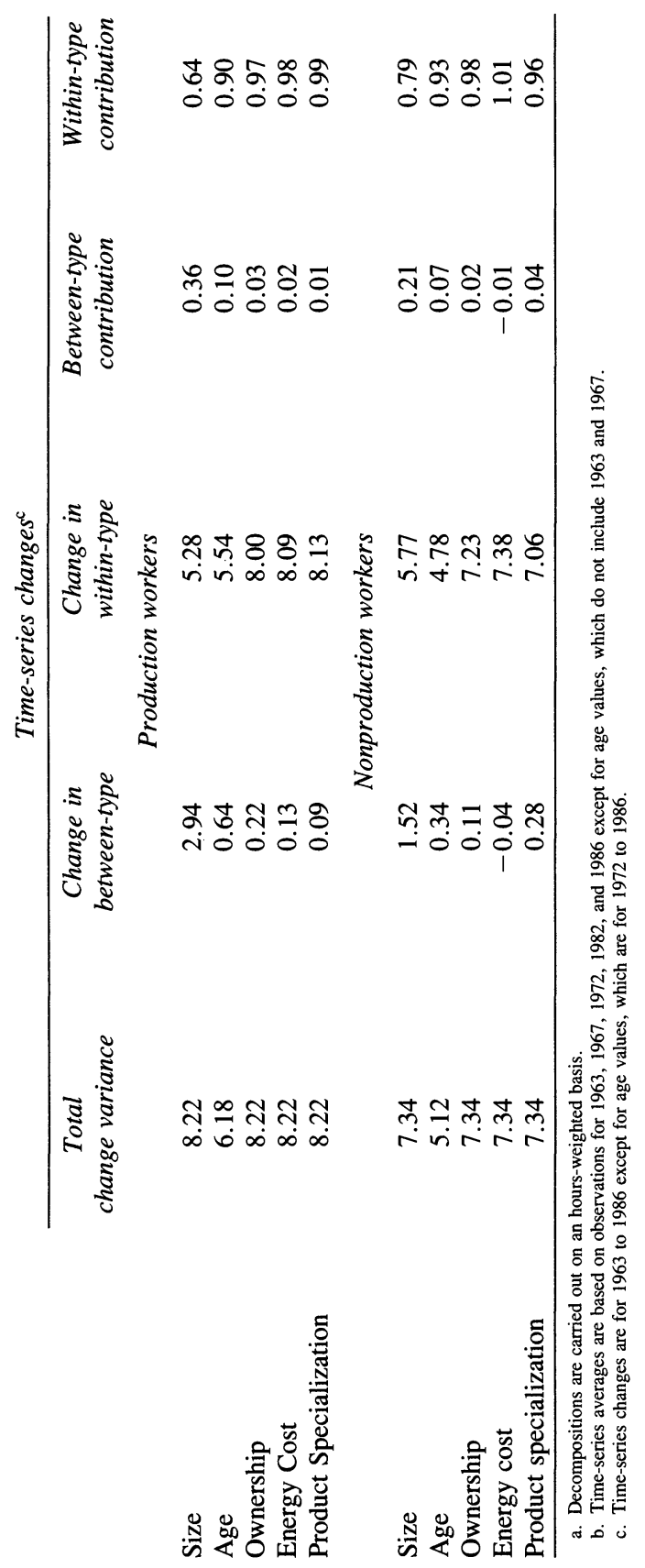


Table 6. Mean Wage Differentials by Plant Size and Year

In 1982 dollars

\begin{tabular}{|c|c|c|c|c|c|c|c|}
\hline Plant size ${ }^{\mathrm{b}}$ & 1963 & 1967 & 1972 & 1977 & 1982 & 1986 & Mean $^{\mathrm{C}}$ \\
\hline \multicolumn{8}{|c|}{ Production workers } \\
\hline 1-19 employees & -0.93 & -0.85 & -1.08 & -1.12 & -1.66 & -0.87 & -1.08 \\
\hline $20-49$ & -1.04 & -0.88 & -1.16 & -1.42 & -1.54 & -1.60 & -1.27 \\
\hline $50-99$ & -1.10 & -1.03 & -1.24 & -1.52 & -1.50 & -1.70 & -1.35 \\
\hline $100-249$ & -0.94 & -0.99 & -1.08 & -1.26 & -1.16 & -1.46 & -1.15 \\
\hline $250-499$ & -0.70 & -0.80 & -0.87 & -0.96 & -0.71 & -0.98 & -0.84 \\
\hline 500-999 & -0.03 & -0.10 & -0.08 & -0.07 & 0.23 & -0.01 & -0.01 \\
\hline $1,000-2,499$ & 1.07 & 0.99 & 1.16 & 1.38 & 1.83 & 2.06 & 1.41 \\
\hline $2,500-4,999$ & 2.15 & & 2.85 & 3.64 & 3.96 & 4.36 & 3.18 \\
\hline $5,000+$ & 2.49 & 2.52 & 3.37 & 4.13 & 4.68 & 4.71 & 3.65 \\
\hline All plants ${ }^{\mathrm{d}}$ & 7.80 & 8.18 & 8.51 & 8.80 & 8.82 & 9.18 & 8.56 \\
\hline \multicolumn{8}{|c|}{ Nonproduction workers } \\
\hline 1-19 employees & -2.90 & -1.13 & -1.43 & -1.22 & -2.59 & -2.23 & -1.92 \\
\hline $20-49$ & -1.05 & -0.50 & -0.75 & -0.75 & -0.92 & -1.38 & -0.89 \\
\hline $50-99$ & -0.49 & -0.41 & -0.70 & -0.84 & -0.82 & -1.37 & -0.77 \\
\hline $100-249$ & -0.56 & -0.74 & -0.87 & -1.06 & -1.04 & -1.31 & -0.93 \\
\hline $250-499$ & -0.46 & -0.67 & -0.92 & -1.06 & -0.89 & -1.09 & -0.85 \\
\hline 500-999 & -0.26 & -0.54 & -0.46 & -0.64 & -0.32 & -0.29 & -0.42 \\
\hline & 0.47 & 0.03 & 0.35 & 0.44 & 0.62 & 0.67 & 0.43 \\
\hline $2,500-4,999$ & 1.14 & 0.82 & 1.60 & 2.22 & 1.88 & 2.24 & 1.65 \\
\hline $5,000+$ & 2.07 & 2.04 & 2.57 & 3.06 & 3.25 & 3.28 & 2.71 \\
\hline All plants & 12.01 & 12.76 & 13.08 & 13.17 & 13.02 & 13.73 & 12.96 \\
\hline
\end{tabular}

a. The mean hourly wage differential is the difference between the mean hourly wage for the indicated size class and the overall mean wage. The mean hourly wage differential is computed on an hours-weighted basis.

b. Plant size is computed as the employment-weighted mean over all sample observations on the plant.

c. The last column reports the simple mean of the six annual observations.

d. The all-plants row reports the overall mean hourly wage.

persion. In sharp contrast, size-class differentials alone account for 36 percent of the change for production workers and 20 percent of the change for nonproduction workers.

\section{A Closer Look at Wage Differentials and Hours Worked by Plant Size}

The dramatic rise in size-wage differentials motivates a more detailed investigation into this aspect of the changing plant-wage structure. Table 6 reports wage differentials by plant size and year for both worker types. Figures 5 and 6 depict mean hourly wages by size class for selected years.

Figures 5 and 6 show that real hourly wages rose steadily for most 
Figure 5. Hourly Wages by Size Class, Production Workers, 1963-86

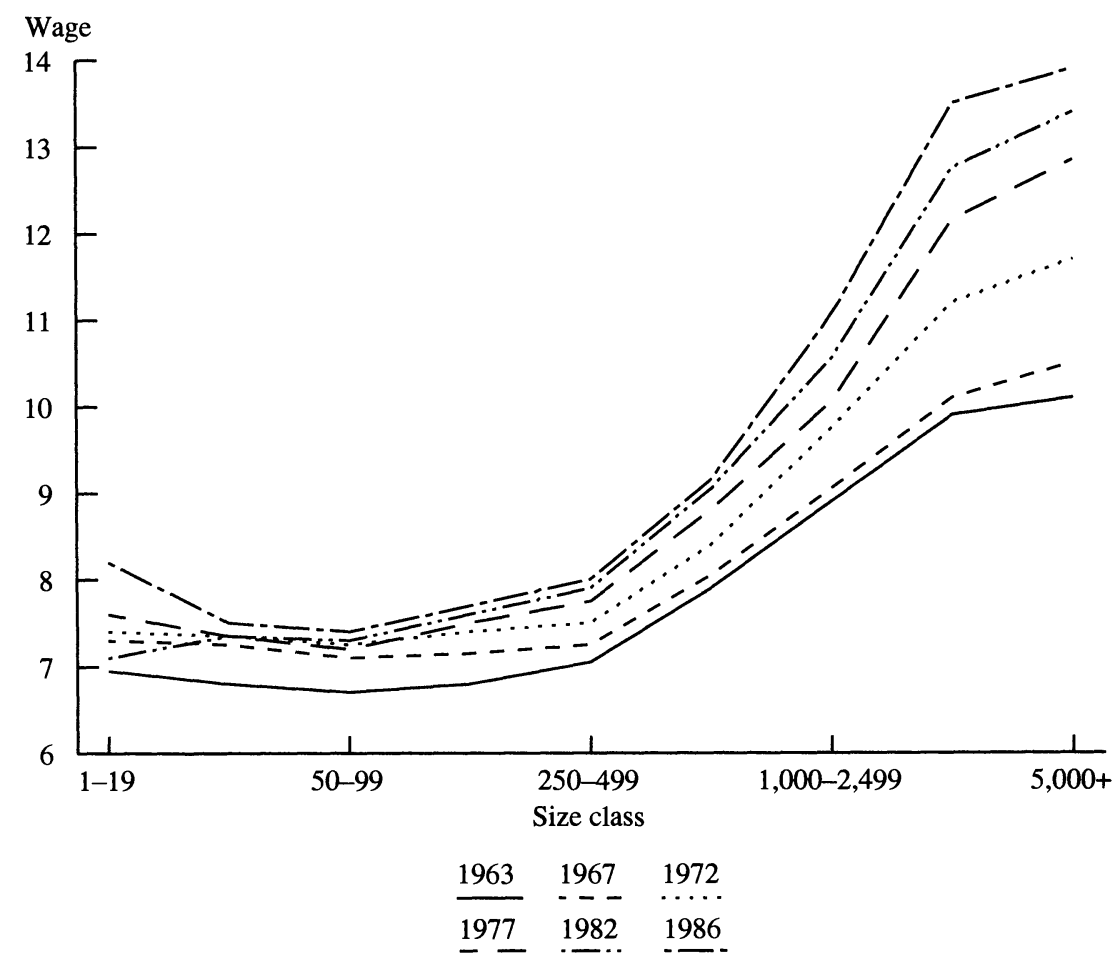

plant size classes over the 1963 to 1986 period. Much larger wage increases took place at larger plants. Table 6 indicates that size-wage differentials expanded continuously after 1967. In 1967 production workers at plants with 20 to 49 employees earned, on average, $\$ 3.40$ less per hour than their counterparts at plants with more than 5,000 employees. By 1986 this wage gap rose to $\$ 6.31$. For nonproduction workers, the corresponding hourly wage gap rose from $\$ 2.54$ in 1967 to $\$ 4.66$ in 1986 . These 1986 wage gaps are enormous relative to the mean hourly wage of $\$ 9.18$ for production workers and $\$ 13.73$ for nonproduction workers.

Our finding of substantial size-wage differentials in any given crosssection is consistent with previous findings in the literature. ${ }^{46}$ The strik-

46. Brown and Medoff (1989). 
Figure 6. Hourly Wages by Size Class, Nonproduction Workers, 1963-86

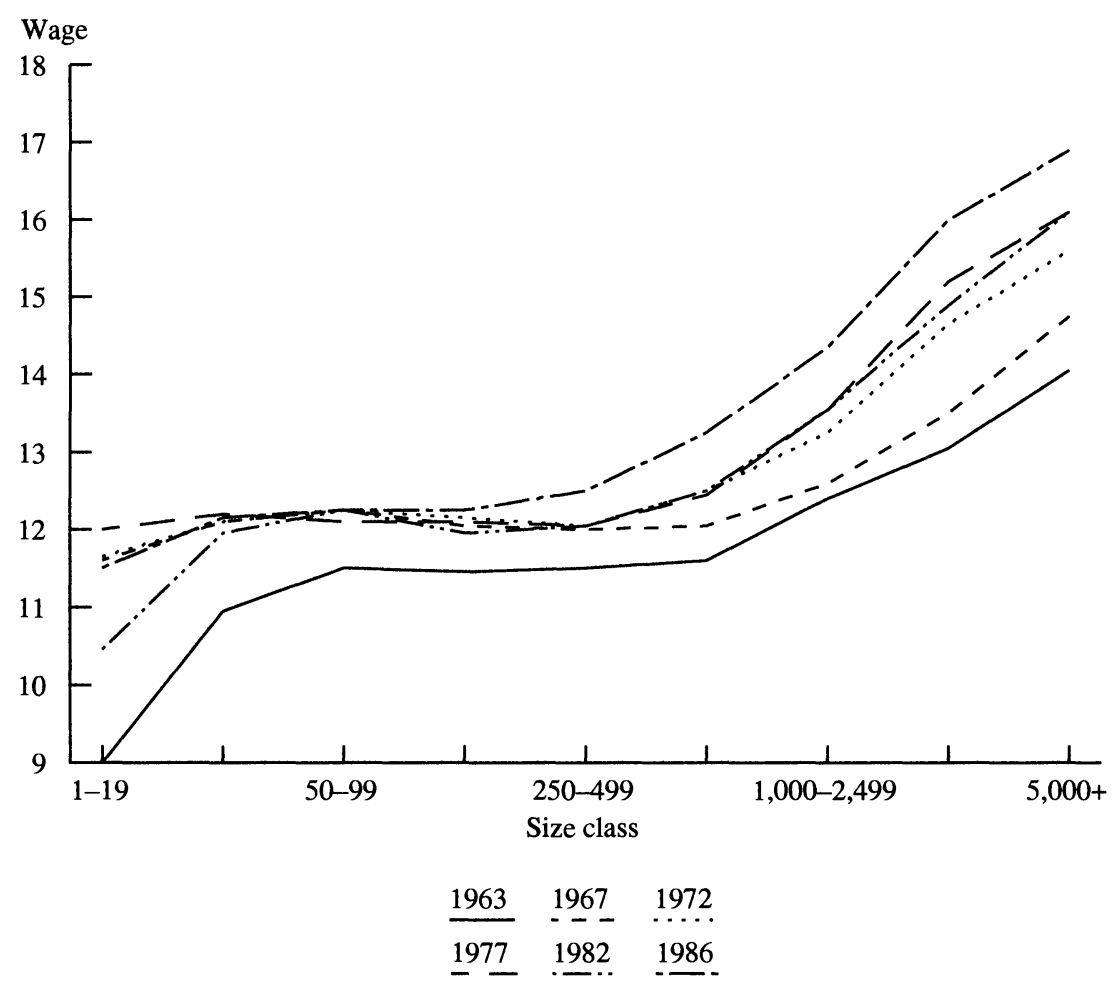

ing and novel finding here is the dramatic and continuous increases in size-wage differentials dating from 1967. This finding and its connection to rising wage dispersion are new facts that any potential explanation of the changing structure of wages must accommodate. As we noted earlier, research based on household surveys finds that skill differentials in the U.S. economy have widened dramatically since the late 1960s. Thus, the time-series changes in the size-wage gap documented in table 6 are consistent with explanations for the gap that stress sorting by worker ability. While efficiency-wage or ability-to-pay explanations for wage differentials by plant size could, in principle, account for the time-series changes, a coherent and plausible explanation along these lines is not evident to us.

The tremendous magnitude of the rise in the size-wage gap indicates 
Table 7. Hours-Weighted Mean Plant Size by Number of Employees, Selected Years, 1963-86

\begin{tabular}{lcccccc}
\hline Measure of plant size $^{\mathrm{a}}$ & 1963 & 1967 & 1972 & 1977 & 1982 & 1986 \\
\hline & \multicolumn{7}{c}{ Mean based on current size $^{\mathrm{b}}$} \\
$\begin{array}{l}\text { 1. Production } \\
\text { worker weights }\end{array}$ & 1,678 & 2,097 & 1,538 & 1,467 & 1,242 & 1,406 \\
$\begin{array}{l}\text { 2. Nonproduction } \\
\text { worker weights }\end{array}$ & 1,734 & 1,827 & 1,568 & 1,480 & 1,357 & 1,458 \\
$\begin{array}{l}\text { Ratio of } \\
\text { line 2 to line 1 }\end{array}$ & 1.55 & 1.62 & 1.33 & 1.34 & 1.69 & 1.74
\end{tabular}

Mean based on average size

3. Production worker weights

4. Nonproduction

worker weights 2,606 3,393 2,045 1,968 2,097

Ratio of

line 4 to line 3

a. Each panel reports the hours-weighted mean plant size for a particular measure of plant size.

b. Current size is simply the number of employees (production workers and nonproduction workers) in the current year.

c. Average size is the employment-weighted mean number of employees for the plant, where the average is computed over all sample observations on the plant.

that sorting by worker ability across plants of different sizes probably increased over time. Table 7 presents evidence consistent with this view. The table shows the evolution of the hours-weighted mean plant size in number of employees for both worker types and using two alternative measures of size. Based on production worker hours and the current size measure, the hours-weighted mean plant size fell from 2,097 employees in 1967 to 1,406 employees in 1986. Most of this decline occurs between 1967 and 1972, but the decline continues after 1972. The nonproduction worker hours-weighted mean plant size also peaks in 1967 and falls dramatically by 1972. However, beginning in 1977 the nonproduction worker hours-weighted mean plant size begins rising. These facts indicate that the rising fraction of total manufacturing hours accounted for by nonproduction workers (table 2) occurs disproportionately at large plants. Thus, at least at the crude level of the distinction between production workers and nonproduction workers, we have direct evidence that average work-force quality at large manufacturing plants has risen relative to average quality at small plants since 1977. 


\section{Full Distribution Accounting for the Changing Plant-Wage}

\section{Structure-Methodology}

The preceding results report bivariate relationships between wages and particular plant characteristics. To provide a more comprehensive characterization of the contribution of observables and unobservables to changes in the plant-wage distribution over time, we use the full distribution accounting methodology developed by Juhn, Murphy, and Pierce. ${ }^{47}$ Using the JMP methodology, we estimate the effects-on various parts of the plant-wage distribution-of changes in the distribution of observable plant characteristics; changes in the wage effects associated with observable plant characteristics; and changes in the distribution of regression residuals.

To understand the methodology, consider the regression equation

$$
W_{e t}=\boldsymbol{X}_{e t} \boldsymbol{\beta}_{t}+u_{e t},
$$

where $W_{e t}$ is the wage at establishment $e$ in period $t, \boldsymbol{X}_{e t}$ is a vector of plant characteristics, and $u_{e t}$ represents the part of the wage unaccounted for by observables. Following JMP, we think of this residual as reflecting the establishment's percentile in the residual distribution, $\omega_{e t}$, and the distribution function of the residuals, $F_{t}\left(\cdot \mid \boldsymbol{X}_{e t}\right)$. Here, we allow for the possibility that the residual distribution function varies with certain observable plant characteristics. It follows from the preceding definitions that

$$
u_{e t}=F_{t}^{-1}\left(\omega_{e t} \mid \boldsymbol{X}_{e t}\right),
$$

where $F_{t}^{-1}\left(\cdot \mid \boldsymbol{X}_{e t}\right)$ is the inverse cumulative residual distribution for plants with characteristics $\boldsymbol{X}_{e t}$ in $t$.

We can now decompose time variation in the plant-wage distribution into three parts: changes in the distribution of plant characteristics (the $\boldsymbol{X}$ 's), changes in the wage effects (the $\boldsymbol{\beta}$ 's) associated with a given set of plant characteristics, and changes in the residual distributions. Defining $\overline{\boldsymbol{\beta}}$ as the average of the estimated wage effects in the cross-section regressions and $\bar{F}\left(\cdot \mid \boldsymbol{X}_{e t}\right)$ as the average cumulative distribution, we can represent this decomposition by 


$$
\begin{aligned}
W_{e t}=X_{e t} \bar{\beta}+\bar{F}^{-1}\left(\omega_{e t} \mid X_{e t}\right)+ & X_{e t}\left(\beta_{t}-\bar{\beta}\right) \\
& +\left(F_{t}^{-1}\left(\omega_{e t} \mid X_{e t}\right)-\bar{F}^{-1}\left(\omega_{e t} \mid X_{e t}\right)\right) .
\end{aligned}
$$

The first two terms in this decomposition capture the contribution of changes in the distribution of observable plant characteristics for fixed wage effects. The third term captures the contribution of changing wage effects. The final term captures the contributions of changes in the distribution of regression residuals that are unexplained by changes in the $\boldsymbol{\beta}$ 's and changes in the distribution of the $\boldsymbol{X}$ 's. We can use the decomposition in (8) to isolate the contribution of these three types of changes to the total change in the wage structure.

To isolate the contribution of changes in the distribution of observable plant characteristics, consider

$$
W_{e t}^{1}=\boldsymbol{X}_{e t} \overline{\boldsymbol{\beta}}+\bar{F}^{-1}\left(\omega_{e t} \mid \boldsymbol{X}_{e t}\right) .
$$

The time path of the distribution over the $W_{e t}^{1}$ represents an estimate of how the changing distribution of observable plant characteristics affects the wage structure.

To generate the marginal contribution of changes in wage effects to changes in the wage structure, consider

$$
W_{e t}^{2}=\boldsymbol{X}_{e t} \beta_{t}+\bar{F}^{-1}\left(\omega_{e t} \mid \boldsymbol{X}_{e t}\right) .
$$

The distribution over the $W_{e t}^{2}$ reflects both wage effects and observable plant characteristics. Now think of calculating the time path of the distribution over the $W_{e t}^{2}$, as well as the time path of the distribution over the $W_{e t}^{1}$. For each of these time paths, we can calculate time series on various summary statistics. Comparing the $90-10$ percentile range, for example, as generated by distributions over the $W_{e t}^{1}$ and the $W_{e t}^{2}$, yields an estimate of the marginal contribution of changing wage effects to changes in the 90-10 range. Similar remarks apply to other measures of inequality.

Likewise, we can generate the marginal contribution of changes in the unobservables to changes in the wage structure by considering

$$
W_{e t}^{3}=\boldsymbol{X}_{e t} \boldsymbol{\beta}_{t}+F^{-1}\left(\omega_{e t} \mid \boldsymbol{X}_{e t}\right)=\boldsymbol{X}_{e t} \boldsymbol{\beta}_{t}+u_{e t}=W_{e t} .
$$

Hence, comparing the time path of the distribution over the $W_{e t}$ to the time path of the distribution over the $W_{e t}^{2}$ yields the marginal contribution of changes in the unobservables to changes in the wage structure. 


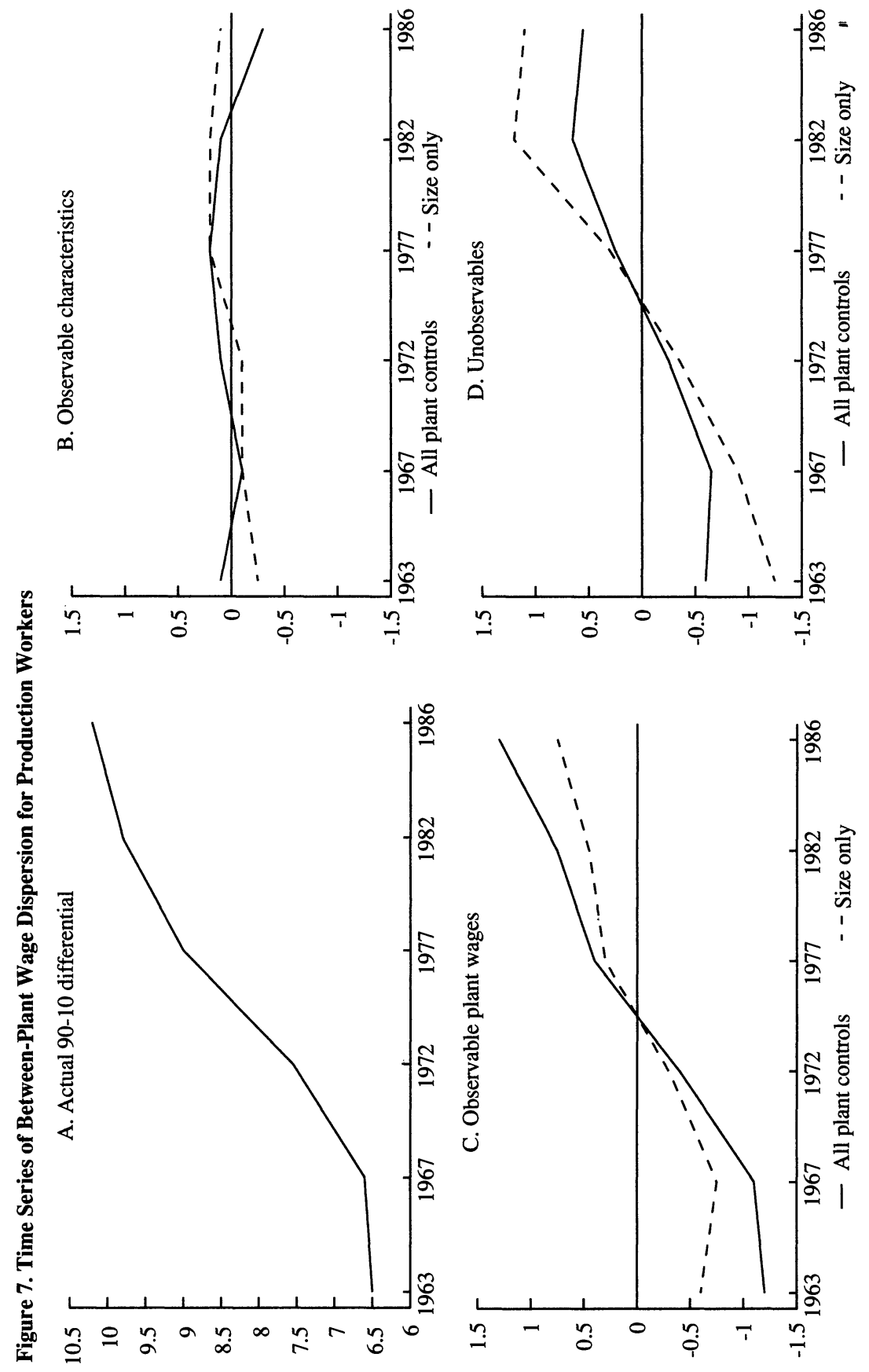




\section{Full Distribution Accounting Results}

The top left panel of figure 7 plots the time series of between-plant wage dispersion for production workers, as measured by the wage differential between the 90th and 10th percentiles of the plant-wage distribution. The 90-10 differential rose from roughly $\$ 6.50$ an hour in 1967 to more than $\$ 10.00$ an hour in 1986 . The increase in the $90-10$ differential holds fairly steady from 1967 to 1982 and then slows between 1982 and 1986.

The other three panels in figure 7 break down the growth in the 9010 plant-wage differential into the three components of the JMP accounting exercise. Each component is measured as a deviation from its overall mean. The regression specification underlying the decomposition represented by the solid curves contains two-digit industry effects, nine region effects, a quartic in size, two ownership types, three energy cost classes, five product specialization classes, and no interaction terms. In this specification, we permit the distribution function of the residuals to vary across two-digit industries. The specification underlying the decomposition represented by the dashed curve contains only the quartic in size (and the year-specific intercept terms) and a residual distribution function that does not vary by industry or any other plant characteristic.

Several interesting results emerge from the time-series decomposition in figure 7 . First, changes in the distribution of observable plant characteristics (holding fixed the wages associated with these characteristics) had little effect over the 1963-86 period on between-plant wage dispersion, as measured by the 90-10 differential.

Second, changes in the wages associated with observable plant characteristics account for two-thirds of the total increase in the 90-10 wage differential. Over the sample period, the $90-10$ wage differential rose by $\$ 3.74$ per hour. Wage effects alone account for a rise in the $90-10$ differential equal to $\$ 2.47$ per hour. The dominant role of observable wage effects in accounting for rising between-plant wage dispersion contrasts sharply with the dominant role of unobservables in accounting for the overall rise in between-worker wage dispersion. Indeed, Juhn, Murphy, and Pierce find that observable wage effects and observable quantity effects combined account for only one-third of the increase in the 90-10 worker wage differential over the 1963-86 time period. ${ }^{48}$

48. Juhn, Murphy, and Pierce (1989). 
Table 8. Observable and Unobservable Components of Changes in the Plant-Wage Structure, Manufacturing Workers, 1963-86

In 1982 dollars

\begin{tabular}{|c|c|c|c|c|}
\hline $\begin{array}{l}\text { Inequality } \\
\text { measure }\end{array}$ & $\begin{array}{c}\text { Total change } \\
\text { 1963-86 }\end{array}$ & $\begin{array}{c}\text { Observable } \\
\text { quantities }\end{array}$ & $\begin{array}{c}\text { Observable } \\
\text { wages }\end{array}$ & Unobservables \\
\hline & \multicolumn{4}{|c|}{ Production workers } \\
\hline Standard deviation & 1.26 & -0.12 & 0.74 & 0.64 \\
\hline $90-10$ differential & 3.74 & -0.20 & 2.47 & 1.46 \\
\hline $90-50$ differential & 3.32 & 0.33 & 1.82 & 1.17 \\
\hline \multirow[t]{2}{*}{ 50-10 differential } & 0.41 & -0.53 & 0.65 & 0.29 \\
\hline & \multicolumn{4}{|c|}{ Production workers (controlling only for plant size) } \\
\hline Standard deviation & 1.26 & -0.05 & 0.51 & 0.80 \\
\hline 90-10 differential & 3.74 & 0.38 & 1.45 & 1.90 \\
\hline 90-50 differential & 3.32 & 0.88 & 1.22 & 1.22 \\
\hline \multirow[t]{2}{*}{ 50-10 differential } & 0.41 & -0.50 & 0.23 & 0.68 \\
\hline & \multicolumn{4}{|c|}{ Nonproduction workers } \\
\hline Standard deviation & 0.81 & -0.14 & 0.31 & 0.51 \\
\hline 90-10 differential & 2.90 & -0.13 & 1.31 & 1.72 \\
\hline $90-50$ differential & 1.46 & 0.05 & 0.71 & 0.70 \\
\hline 50-10 differential & 1.44 & -0.18 & 0.60 & 1.02 \\
\hline
\end{tabular}

Source: Author's calculations. See text for a description of the regression specifications that underlie the calculations in this table.

Third, the wage effects associated with plant size alone account for a remarkably large fraction of the total increase in between-plant wage dispersion. According to the dashed curve in the lower left panel of figure 7 , changing wage effects associated with plant size account for $\$ 1.45$ of the $\$ 3.74$ increase in the $90-10$ plant-wage differential. Thus the dramatic expansion of size-wage differentials that we found in previous tables accounts for nearly 40 percent of the total increase in between-plant wage dispersion.

An attractive feature of the JMP methodology is that it enables one to quantify the effect of changes in the observables and unobservables on all parts of the wage distribution. Table 8 exploits this feature of the methodology to report the decomposition of time-series changes in the 90-50 and 50-10 wage differentials. Two facts stand out in the table.

First, for production workers, observable characteristics and wages together account for over 60 percent of the increase in between-plant dispersion for all of the reported measures. For nonproduction workers, observable characteristics and wages account for a smaller but still 
substantial fraction of the time-series change in the various measures of between-plant wage dispersion.

Second, almost 90 percent of the increase in between-plant wage dispersion among production workers occurs in the upper half of the distribution. This latter finding is interesting in the context of recent controversies about whether the economy has been providing too many "bad jobs." 49 According to the top panel in table 8, changes in the distribution of observable plant characteristics between 1963 and 1986 actually contributed to a substantial decrease in the differential between mean wages at the average plant (50th percentile) and mean wages at low-wage plants (10th percentile). In other words, the manufacturing sector is (in 1986) providing relatively fewer jobs at the type of plants that traditionally provided low-wage employment opportunities. ${ }^{50}$ Note that the small increase in the 50-10 differential over the 1963-86 period also indicates that the erosion of the real minimum wage played little part in rising wage inequality in the manufacturing sector.

\section{Interpretation of Findings}

At this point in our investigation, we have accumulated several facts that help discriminate between the skill-biased technical change explanation and the trade growth/product demand shift explanation for rising wage inequality in the U.S. economy. These facts are as follows: One, the manufacturing sector experienced dramatic and continuous expanansion of wage differentials by plant size from 1967 to 1986. These rising size-wage differentials account for about 40 percent of the overall increase in between-plant wage dispersion among production workers and a large fraction of the increase among nonproduction workers. Two, the manufacturing sector experienced a sharp leftward shift in the distribution of hours worked by plant size after 1967. Most of this shift occurred by 1972. Since 1977 the distribution of hours worked by nonproduction worker hours has reversed course and shifted substantially to the right. Three, the manufacturing sector experienced a pronounced upgrading of labor skill intensity, as indicated by changes in the educational and occupational mix of manufacturing workers. Four,

49. See, for example, Bluestone and Harrison (1988).

50. In this context, it is useful to observe that the median real wage for manufacturing jobs has risen over our sample period. 
since 1977 improvements in work-force quality have occurred disproportionately at large manufacturing plants. Five, in addition, research based on household surveys points to steady relative demand growth for more highly skilled workers in recent decades.

These facts are consistent with the view that skill-biased technical change has been the major driving force behind rising wage inequality in the United States. The facts are difficult to square with the view that product demand shifts have been the major driving force behind rising wage inequality. Given sharply rising skill and size differentials, an explanation based solely on product demand shifts is very difficult to reconcile with the shift in the distribution of hours worked toward small plants, and the relative increase in the average work-force quality of large plants. To accommodate the rising skill differential, the product demand shift story must postulate an increase in the demand for products that intensively utilize high-skill labor inputs. If this product demand increase impinges directly on large plants, then the distribution of hours worked will shift toward large plants. This implication is sharply at odds with the leftward shifts in the distribution of hours worked by plant size. If this product demand increase directly affects only the subset of small plants that intensively utilize high-skill labor (and not large plants), then large plants will substitute away from high-skill labor and the relative work-force quality of large plants will deteriorate. This prediction is sharply at odds with evidence that average work-force quality at large plants rose relative to work-force quality at small plants. Finally, explanations for rising wage inequality based on product demand shifts offer no apparent explanation for the explosion of withinplant wage dispersion among nonproduction workers documented in table 3 .

In contrast, the skill-biased technical change story that we outlined earlier predicts rising skill differentials, rising size-wage differentials, and rising average work-force quality at large plants. This story also accommodates the leftward shift in the distribution of hours worked by plant size. ${ }^{51}$ Skill-biased technical change is also suggested by the

51. Reasonable assumptions about the marginal rate of technical substitution in the production function between high-skill and low-skill workers can lead to either a rightward or leftward shift in the distribution of hours worked by plant size in response to skill-biased technical change. The skill-biased technical change story carries stronger implications about 
pattern of increasing wage dispersion that appears in table 3, as we argued earlier. However, the simple skill-biased technical change story developed earlier does not seem sufficiently rich to explain the explosion of within-plant wage inequality among nonproduction workers. This observation suggests to us that a shift toward more ability-sensitive modes of production has played an important role in rising wage inequality.

Another finding not obviously explained by our skill-biased technical change story is the difference between the timing of changes in the distribution of hours worked by plant size and the timing of changes in size-wage differentials. As figures 5 and 6 indicate, size-wage differentials rise continuously after 1967 . But, as figure 4B and table 7 indicate, most of the leftward shift in the size distribution of hours and employment occurs between 1967 and 1972. Several observations help reconcile these timing differences with the skill-biased technical change story. First, a substantial fraction (approximately one-third) of the overall increase in size-wage differentials also occurs between 1967 and 1972. Second, the leftward shift in the size distribution of hours and employment continues after 1972, albeit at a slower rate. Preliminary investigation (see footnote 21) indicates that the sharp 1967-72 decline in the hours-weighted mean plant size partly reflects special factors that are unrelated to the structural changes on which this study focuses. Third, skill-biased technical change carries no strong implications for shifts in the distribution of hours worked by plant size. Our skill-biased technical change story carries stronger implications regarding changes in the skill composition of labor inputs by plant size. Consistent with our story, tables 4 and 7 show systematic shifts toward greater reliance on nonproduction workers at large plants.

\section{Further Investigation of the Plant-Wage Structure: Size, Trade, and Union Effects}

In this section, we directly investigate the role of changing patterns of unionization and international trade on the plant-wage structure. We

the distribution of output by plant size and the rate of growth of output per worker by plant size. We have not yet investigated these implications. 
Table 9. Mean Wage Differentials by Plant Size and Year, Controlling for Plant and Industry Characteristics ${ }^{\mathrm{a}}$

In 1982 dollars

\begin{tabular}{lrrrrrr}
\hline \multicolumn{1}{c}{ Plant size } & \multicolumn{1}{c}{1975} & 1977 & \multicolumn{1}{c}{1979} & \multicolumn{1}{c}{1982} & 1984 & 1986 \\
\hline & \multicolumn{5}{c}{ Production workers } \\
$1-19$ employees & -0.46 & -0.26 & -0.64 & -1.05 & -0.32 & -0.41 \\
$20-49$ & -0.40 & -0.53 & -0.75 & -0.89 & -0.70 & -1.09 \\
$50-99$ & -0.33 & -0.65 & -0.69 & -0.88 & -0.76 & -1.20 \\
$100-249$ & -0.37 & -0.53 & -0.60 & -0.65 & -0.53 & -1.00 \\
$250-499$ & -0.23 & -0.40 & -0.35 & -0.37 & -0.14 & -0.59 \\
$500-999$ & -0.05 & -0.13 & -0.05 & 0.05 & 0.33 & -0.07 \\
$1,000-2,499$ & 0.29 & 0.35 & 0.51 & 0.69 & 1.16 & 0.99 \\
$2,500-4,999$ & 0.97 & 1.18 & 1.33 & 1.47 & 1.78 & 1.75 \\
$5,000+$ & 0.57 & 0.97 & 1.24 & 1.63 & 1.52 & 1.62 \\
& & & Nonproduction & workers & & \\
$1-19$ employees & -1.82 & -1.86 & -1.46 & -3.08 & -1.56 & -2.56 \\
$20-49$ & 0.10 & -0.64 & 0.18 & -0.49 & -0.33 & -0.79 \\
$50-99$ & 0.45 & -0.33 & 0.03 & 0.18 & 0.00 & -0.50 \\
$100-249$ & -0.11 & -0.27 & -0.34 & -0.04 & -0.03 & -0.40 \\
$250-499$ & -0.22 & -0.39 & -0.46 & 0.03 & 0.18 & -0.45 \\
$500-999$ & -0.32 & -0.37 & -0.23 & 0.21 & 0.51 & -0.01 \\
$1,000-2,499$ & 0.05 & 0.46 & 0.06 & 0.73 & 1.03 & 0.90 \\
$2,500-4,999$ & 0.88 & 1.91 & 1.17 & 1.00 & 2.03 & 2.22 \\
$5,000+$ & 0.98 & 1.50 & 1.06 & 1.46 & 1.37 & 1.58 \\
\hline
\end{tabular}

a. The mean hourly wage differential is the difference between the mean hourly wage for the indicated size class and the overall mean wage for the year. The mean hourly wage for each size-year entry is the coefficient from plant-level regresssions with size class and year interacted, controlling for other plant and industry characteristics. All regressions are estimated by OLS on a pooled time-series, cross-sectional data set containing plant-level observations for the years 1975, 1977, 1979, 1982, 1984, and 1986. The other controls are class variables for four-digit industry, plant age, region, ownership type, product specialization, energy intensity; and industry-level work-force controls (percent female, mean experience, mean education), industry-level import penetration ratio and export share, union density, and capital-labor ratio. Union density is from the CPS at the two-digit level. The import and export variables are from the NBER Trade Data Set at the four-digit level. Standard errors of coefficients for production workers range from 0.11 to 0.12 . Standard errors for nonproduction workers range from 0.24 to 0.29 .

also reestimate the size-wage differentials, while controlling for a host of plant-level and industry-level observables, to examine the robustness of our earlier findings.

\section{Size-Wage Differentials with Extensive Controls}

Table 9 reports estimated size-wage differentials in the presence of plant-level and industry-level controls. These differentials are estimated from a pooled time-series cross-section regression containing year effects; plant-level controls for age, energy cost, product specialization, and four-digit industry; and additional time-varying industry-level mea- 
sures of union membership density, work-force characteristics, the import penetration ratio, and exports' share of shipments. The reported estimates are coefficients on the size-class indicators interacted with the year effects.

Comparing tables 6 and 9 reveals that the controls substantially reduce the production worker size-wage differentials, especially for the class of more than 5,000 employees. In 1986, for example, the production worker wage differential between plants with 20 to 49 employees and plants with 2,500 to 4,999 employees is $\$ 5.96$ without controls and $\$ 2.84$ with controls. Comparing tables 6 and 9 reveals that the controls less successfully account for the nonproduction worker size-wage differentials. The controls also typically account for a smaller portion of the growth in the size-wage differentials and, in some cases, lead to larger increases in the differentials. For example, between 1977 and 1986 the production worker wage differential between plants with 20 to 49 employees and plants with 2,500 to 4,999 employees rises by $\$ 0.90$ without controls and by $\$ 1.13$ with controls. In short, the results in table 9 reinforce our earlier findings on the impressive magnitude and dramatic growth of size-wage differentials. A convincing explanation for rising wage dispersion across plants and workers will provide a coherent interpretation of rising size-wage differentials.

\section{Trade and Union Effects}

Turning to the effects of trade patterns and unionization on the wage structure, we have argued that the accumulated evidence is unfavorable to the trade growth-product demand shift explanation and the deunionization explanation for rising wage inequality. It remains to be seen whether a closer examination of the data will reveal important effects of trade shocks or deunionization on the plant-wage structure.

Our ability to directly investigate the impact of trade effects and unionization rates on the plant-wage structure is restricted by data limitations, particularly with respect to union effects. The LRD contains no information on union presence at the plant. Neither does the LRD contain reliable information regarding exports by plant. Our methodology here is based on the presumption that differential changes in trade patterns or unionization rates across industries should be reflected in systematic responses of the plant-wage structure within manufacturing. 
These responses can arise either because of imperfect labor mobility across industries and plants, or because trade and union shocks lead to changes in work-force quality that are not captured by our crude controls. Even if labor is imperfectly mobile, there may be significant crossindustry effects missed in our analysis. ${ }^{52}$ Nevertheless, if changing trade patterns or unionization rates have played an important role, then we should be able to detect direct effects of these changes on the structure of wages in the impacted industries.

To investigate trade effects, we match detailed (four-digit) industrylevel information on the time series of imports and exports to the plantlevel data using the plant's four-digit industry code. We also match two-digit industry-level figures for union membership density to the plant-level data. The time span covered by the union density data limits our analysis to the $1975-86$ period. By interacting the industry-level data with observable plant characteristics, we investigate whether industry-level variation in the import penetration ratio, exports' share of shipments, or union membership density accounts for a significant fraction of the increase in between-plant wage dispersion.

Table 10 presents estimated wage effects associated with the interaction of industry-level trade and union variables with plant characteristics. The wage effects are estimated by OLS in a pooled time-series cross-sectional regression specification that includes year effects, 450 four-digit industry effects, time-varying industry measures of workforce quality and capital intensity, and a battery of plant-level characteristics. While virtually all of the reported interaction coefficients are statistically significant, the estimated impact of the trade and union variables on the plant-wage structure is quite modest.

Consider, for example, the interactions of the industry-level variables with plant size. For production workers, an increase in an industry's import penetration ratio is associated with a rise in the size-wage differential. The relevant estimated coefficient is 0.000235 . (The coefficients on plant size in the table are multiplied by $10^{3}$ - see the notes to table 10.) This estimate implies that even a large increase in the import penetration ratio, say ten percentage points, increases the sizewage differential between a plant with 50 workers and a plant with

52. Revenga (1989). 
5,000 workers by less than $\$ 0.12$ per hour. ${ }^{53}$ Carrying out a similar exercise for a 10 percentage point increase in the export share, the estimated effect on the size-wage differential is only $\$ 0.04$ per hour. ${ }^{54}$ These effects are tiny relative to observed increases in the size-wage differential and overall between-plant wage dispersion.

Changes in industry-level union density also have small estimated effects on the size-wage differential. Union threat-effect models of wage determination predict that a higher unionization rate reduces the sizewage differential. ${ }^{55}$ The argument is that large nonunion plants pay union wages because they face a strong threat of unionization, whereas small nonunion plants facing a lesser threat are less compelled to match the union wage. Accordingly, an increase in industry-wide union density disproportionately increases the wages of small plants and thus narrows the size-wage differential. The negative estimated coefficient on the size-union interaction term is consistent with this hypothesis. However, the magnitude of the effect is trivial. A 10 percentage point increase in union density would, according to the estimate, reduce the wage differential between a plant with 50 employees and a plant with 5,000 employees by one penny an hour. ${ }^{56}$

The largest interaction effect reported in table 10 is the interaction between export share and energy use. A 10 percentage point increase

53. This calculation is the product of the estimated coefficient, 0.000235 , the change in the import penetration ratio under consideration, 0.10 , and the difference in plant sizes under consideration, 4,950.

54. This calculation is the product of the estimated coefficient, 0.000083 , the change in the export penetration ratio under consideration, 0.10 , and the difference in plant sizes under consideration, 4,950.

55. Freeman and Medoff (1984); and Podgursky (1986).

56. This calculation is the product of the estimated coefficient, -0.0000002 , the change in union density under consideration, 10 , and the difference in plant sizes under consideration, 4,950. As noted earlier, unions may have an important effect on within-plant wage dispersion. In regression results not reported here, we investigated the relationship between industry-level unionization rates and industry level-measures of within-plant wage dispersion (generated by the method described under "Between-Plant and Within-Plant Components of Manufacturing Wage Dispersion"'). We considered numerous specifications that allowed for different combinations of year effects, industry effects, trade variables, workforce composition variables, and plant composition variables. We found no evidence that union density has a statistically significant effect on within-plant wage dispersion in any of our regression specifications, although several of the other variables were significantly related to within-plant dispersion. 


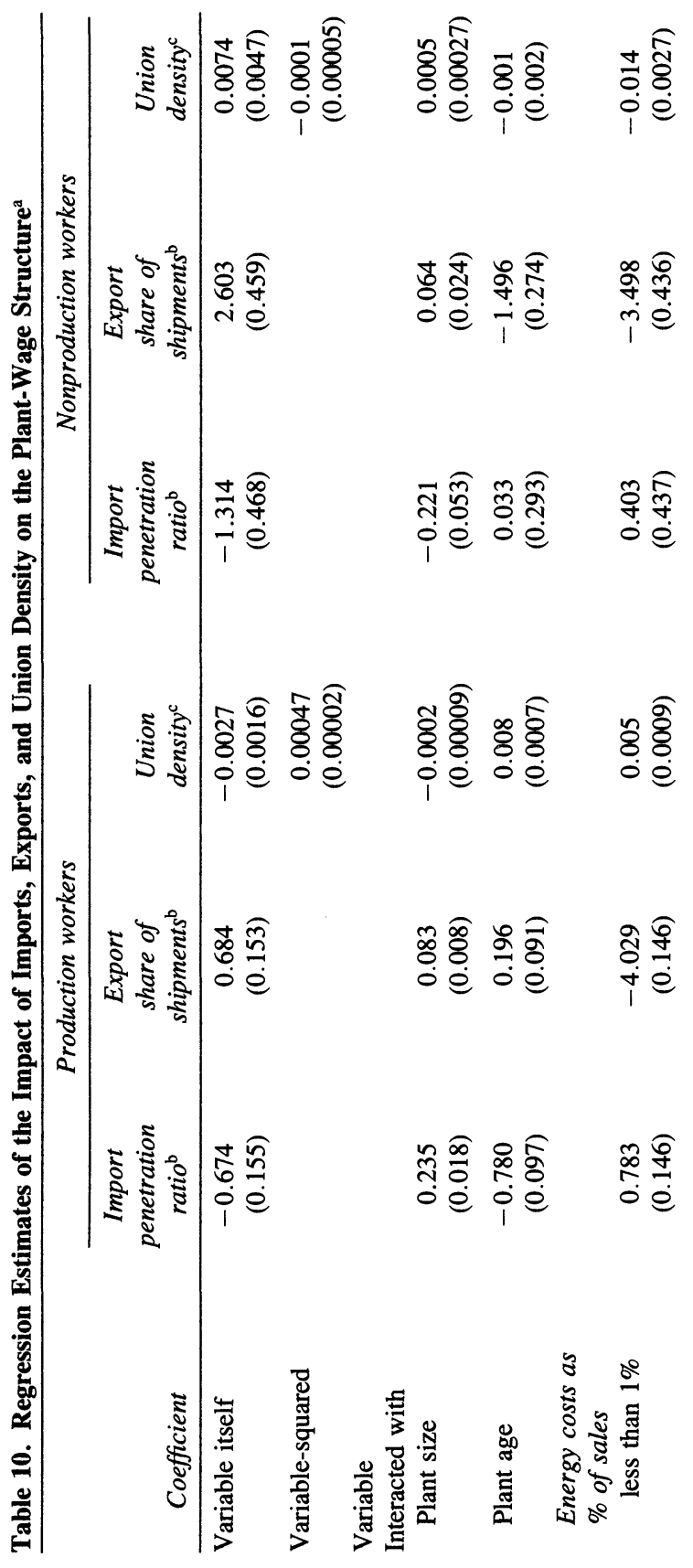




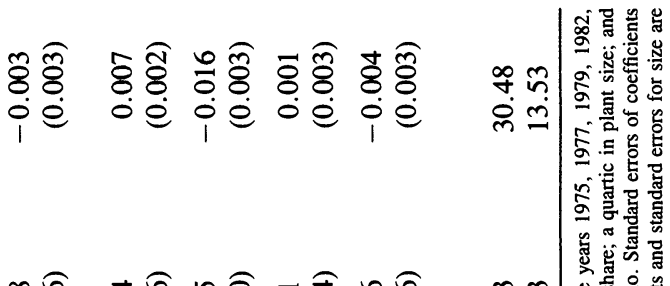

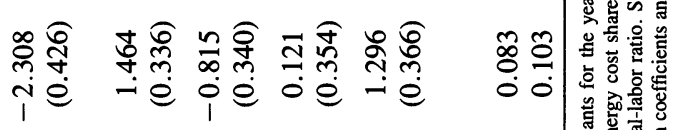

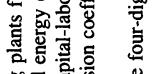
๙ิণ

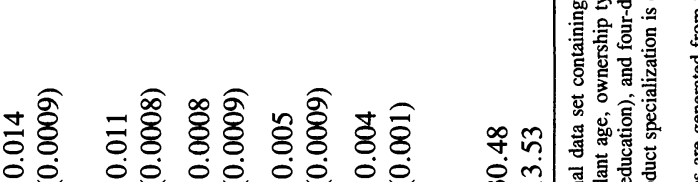

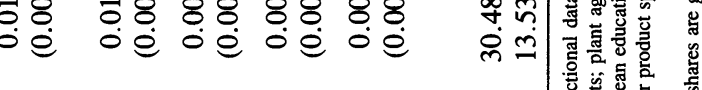

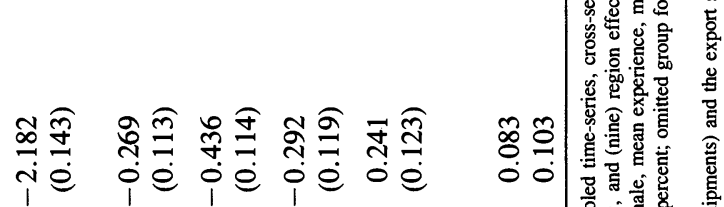
i

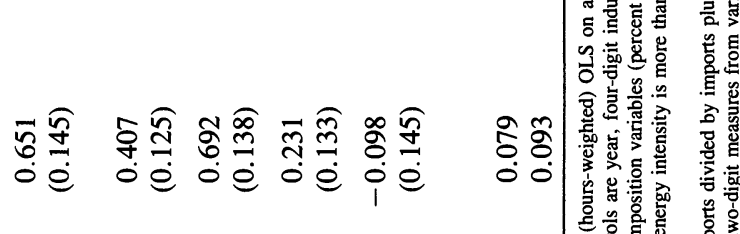

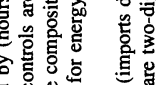
$\begin{array}{llllll} & & & & \\ 0\end{array}$ 
in the export share is estimated to increase the production worker wage differential between plants with low energy costs (less than 1 percent of sales) and plants with high energy costs (greater than 5 percent of sales) by $\$ 0.40$ per hour. ${ }^{57}$ For nonproduction workers, this same conceptual experiment is estimated to increase the energy cost wage differential by $\$ 0.34$ per hour. In both cases, the effects are modest relative to observed increases in plant-wage differentials over this time interval. We stress that these effects are by far the largest ones in the table.

In sum, these results indicate that changing patterns of trade and unionization played a small role in recent changes in the plant-wage structure. To restate the point, neither trade nor union effects appear to account for much of the rise in between-plant wage dispersion or the size-wage differential. Conceivably, a careful treatment of potential simultaneity and measurement problems associated with our trade and union variables might yield different inferences, but the results in table 10 are fully consistent with the other evidence in this paper that neither trade shocks nor deunionization explain the growth of wage dispersion. One expects the impact of changing trade and (private sector) unionization patterns on the wage structure to be even smaller outside of the manufacturing sector. As a caveat, we note that the results in table 10 do not speak to the issue of whether trade growth caused important changes in the distribution of employment across plants with different characteristics. We leave this issue for future research.

\section{Conclusion}

To conclude, we summarize the central results and main conclusions to emerge from the research in this paper.

First, between-plant wage dispersion is a large component of overall wage dispersion. Over one-half of the total wage variance in the U.S. manufacturing sector is accounted for by the dispersion in mean wages across plants. In addition, between-plant dispersion accounts for 48

57. This calculation is the product of the estimated coefficient on the dummy variable for energy costs less than 1 percent of sales, -4.089 , and the change in the export share under consideration, 0.10 . 
percent of the growth in overall manufacturing wage dispersion from 1975 to 1986.

Second, there are striking differences across production and nonproduction workers in the relative contributions of between-plant and within-plant components to overall wage dispersion and to the growth in overall wage dispersion. For production workers, between-plant dispersion accounts for most of the cross-sectional dispersion at any point in time and for more than 90 percent of the time-series increases from 1975 to 1986. In contrast, for nonproduction workers, within-plant wage dispersion accounts for most of the cross-sectional dispersion and for most of the time-series increase in cross-sectional dispersion. These findings cast strong doubt on the view that rising wage inequality reflects the weakening of social norms that constrain wage dispersion within the firm. This view implies rising within-plant inequality for both types of workers, an implication sharply at odds with the virtual absence of rising within-plant wage inequality for production workers. These findings also cast doubt on the view that deunionization played a significant role in rising wage inequality, since deunionization would seem to imply disproportionate increases in within-plant inequality for production workers.

Third, between-plant dispersion is not due simply to random effects or unobserved plant characteristics. Over half of between-plant wage dispersion in a given year can be accounted for by basic plant characteristics such as industry, size, age, region, ownership type, degree of product specialization, energy costs, and capital intensity. Furthermore, these plant characteristics account for over two-thirds of the timeseries increase in between-plant dispersion among production workers and a large fraction of the increase among nonproduction workers.

Fourth, the most important plant characteristic in terms of its ability to explain wage dispersion is plant size. Rising size-wage differentials explain about 40 percent of the overall rise in between-plant wage dispersion for production workers over the 1963 to 1986 time period. The production worker wage differential between plants with more than 5,000 employees and plants with 20 to 49 employees rose from $\$ 3.53$ an hour (1982 dollars) in 1963 to $\$ 6.31$ an hour in 1986 . A noteworthy aspect of the time-series increase in size-wage differentials is that it accompanies a marked leftward shift in the distribution of employment and hours worked by plant size. 
Fifth, a direct investigation into the impact of changing industry patterns of unionization and international trade revealed little role for deunionization and trade growth in accounting for changes in the manufacturing sector's plant-wage structure. Furthermore, we found no evidence that cross-sectional and time-series variation in industry-level union density is associated with variation in within-plant wage dispersion. We also note that any product demand shift explanation, whether or not based on trade factors, is difficult to reconcile with the shift in the distribution of hours worked toward small plants and the relative increase in average work-force quality at large plants in the manufacturing sector.

Combining these findings with the findings of previous research discussed in the introduction points toward skill-biased technical change as the major driving force behind rising wage inequality in the United States. Skill-biased technical change stories can explain the rising skill differential, the rising size-wage differential, the shift toward modes of production that more intensively utilize nonproduction labor inputs, observed shifts in the distribution of hours worked and employment by plant size, steady relative demand growth for more experienced and more educated workers, the steady growth in wage inequality within experience-education-gender groups, and the age-neutral character of rising within-group wage inequality.

Naturally, there are caveats to these interpretations of our results, especially regarding our conclusion that changing trade patterns played little role in the evolution of the plant-wage structure or the rise in wage inequality. Our conclusion on trade effects is essentially a statement that shifts in relative product demand across plants and across industries within manufacturing have not been a major driving force behind rising wage inequality or the other phenomena documented in this paper. Shifting trade patterns may have played important roles through channels other than shifts in relative product demand across plants and industries within manufacturing. One potentially important consequence of weakening barriers to international trade is production outsourcing of intermediate goods that are low-skill labor intensive. Increased outsourcing is consistent with our key findings. For example, suppose large plants initially produced both intermediate and final goods, and that intermediate goods are low-skill intensive. Then outsourcing of intermediate goods produced at large plants could lead to an increase 
in the size-wage differential, an increase in the skill-wage differential, downsizing of large manufacturing plants, and increased average labor quality at large plants. Another potentially important aspect of shifting trade patterns that we have not investigated involves changes in the structure of wages between the manufacturing and the nonmanufacturing sectors of the economy. ${ }^{58}$ More generally, since our empirical analysis is restricted to the manufacturing sector, factors outside of manufacturing that influence wages within manufacturing are neglected. Evaluating these links between changing trade patterns and the wage structure requires further research.

\section{Appendix A: Data}

The LRD is a comprehensive probability sample of establishments in U.S. manufacturing industries. An establishment is defined as a single physical location engaged in manufacturing activity. The LRD is basically a series of contiguous five-year panels with annual survey data on manufacturing establishments, plus census-year data on the universe of manufacturing establishments. Census years in the LRD are 1963, 1967, 19.72, 1977, and 1982. Annual data are available from 1972 onward. From the census-year universe, the bureau draws a sample of establishments which are then surveyed during five successive years. This five-year panel, which commences two years after a census year, comprises the sample of establishments that make up the Annual Survey of Manufactures (ASM). New establishments are added to the panel as it ages to incorporate births and to preserve the representative character of the panel. In 1977 the ASM sample included roughly 70,000 of the 360,000 establishments in manufacturing industries. These sampled establishments accounted for 76 percent of manufacturing employment. The only manufacturing establishments excluded from the sampling frame of the ASM are those with fewer than five employees. These establishments account for 1 percent of manufacturing employment, based on tabulations from either the Census of Manufactures or County Business Patterns.

For census years $(1963,1967,1972,1977,1982)$, we used the com-

58. Murphy and Welch (1991). 
plete census for our tabulations and analysis. For the selected noncensus years $(1975,1979,1984$, and 1986), we used the ASM sample and the given sample weights to make tabulations comparable. Some establishments were excluded from the analysis. First, we excluded establishments with industry codes outside of manufacturing. Second, we excluded establishments in a year that did not have positive economic activity (that is, nonzero shipments, employment, and hours). After these restrictions the number of establishments in the sample (a census year) is 327,143 in 1982 and 52,323 in 1986 (an ASM year). For analysis involving production (nonproduction) workers, an establishment was excluded in any year in which the mean plant hourly wage for production (nonproduction) workers was less than 75 percent of the minimum wage or more than 250 in 1982 dollars. For production workers, these criteria resulted in the exclusion of 5.5 percent of the establishments in 1982 and 0.4 percent of the establishments in 1986. In terms of hours worked, these criteria resulted in the exclusion of 1.7 percent of hours in 1982 and 0.3 percent of hours in 1986.

The mean production worker hourly wage is constructed for each plant by dividing total wages for production workers by total production worker hours, where both data items are reported in the LRD. In the LRD, total wages means salaries, wages, commissions, dismissal pay, paid bonuses, vacation and sick leave pay, and the cash equivalent of compensation paid in kind. Salaries and wages do not include supplementary labor costs such as employer's social security contributions, other legally required expenditures, or payments for voluntary employer programs such as health insurance.

For nonproduction workers, data limitations required a different procedure. Reported data items in the LRD include nonproduction worker employment for mid-March and total annual wages (defined as above). Annual nonproduction worker hours are not available in the LRD. To estimate them, we first generated annual hours per nonproduction worker for the CPS by two-digit industry. We then estimated nonproduction worker hours as the product of nonproduction worker employment (LRD) and the annual hours per nonproduction worker in the industry (CPS).

Some of the establishment-level data in the LRD is imputed. For all establishments, Internal Revenue Service and Social Security Administration information is typically available for name, address, payroll, employment, gross business receipts, and industry; these data items are 
generally not imputed. Accordingly, the measures we use based upon this information are quite reliable. For this paper, our measures of size (average and current), age, region, ownership type, and industry fall into this category. ${ }^{59}$ Imputation procedures for missing data items are based on industry average ratios of the missing item to payroll and sales.

Data for administrative record (AR) cases are based entirely on information from the IRS and SSA. AR cases are small establishments, typically with fewer than five employees, that have been excused from filing census forms. All data items other than those from IRS and SSA records are imputed for AR cases. These cases account for only 3 to 4 percent of total manufacturing employment in a typical census year. Also, recall that there are no AR cases in the ASM sample.

Establishments other than AR cases can also have some data imputed in census or ASM years. The need for imputation results from differences in filing requirements across establishments (some small establishments get abbreviated forms to reduce filing burdens) and the failure of some firms to fully report on all data items. Small establishments receive less attention than large establishments in terms of edits and follow-ups for missing data. If a large plant fails to report an item, the census is likely to contact the plant to obtain the information. The nature and extent of imputation bias is the focus of current research at the Center for Economic Studies at the Bureau of the Census.

Imputation and related missing data problems potentially generate a systematic bias in our calculated size-wage differentials. Small establishments are more likely to have imputed data and, since imputation is based on average industry ratios, estimated wages for small plants will be biased upward. Also there are a number of plants that report zero nonproduction workers. This reporting pattern seems to be related to two distinct phenomena. First, some small plants lump nonproduction workers together with production workers. Since nonproduction worker wages are on average higher, this reporting pattern will bias upward the wages of small plants. Second, some multiunits firms appear to report nonproduction worker employment at auxiliary and administrative manufacturing plants rather than at the production plants. Since

59. The age variable is based upon the first appearance of the establishment in the manufacturing universe - that is, the first census year that the establishment appears. 
the auxiliary plants are not included in the LRD, this reporting pattern generates a downward bias in the wages for nonproduction workers at large plants. In sum, there are several factors that seem to work in the same direction of generating a downward bias in our calcuated sizewage differential. We believe that these biases are small.

\section{Appendix B: Measurement Error and the Wage Variance Decomposition}

Previous investigations of measurement error in the earnings data from household surveys like the CPS find significant mean reversion. In other words, the covariance between the measurement error in earnings and true earnings is negative ${ }^{60}$ Unfortunately, the results in these previous studies are not directly applicable to our decomposition of the wage variance into between-plant and within-plant components because of differences in the sampling frame, the compensation measures considered, and the experimental design underlying earlier measurement error studies. To the best of our knowledge, there are no data sets with matched employer and worker observations on hourly earnings that are close analogs to the LRD and CPS data used in this study.

The most comparable data set appears to be a special supplement to the January 1977 CPS. In this supplement, a subset of the regular CPS interviewees were queried for the name and address of their employer. Employers were then contacted and asked an identical set of questions about individual workers' wages and other items. From the matched data, one can construct employer and worker measures of usual hourly earnings based on a direct question for hourly wage earners and based on typical hours per week and earnings per week for other workers. These data differ from the CPS and LRD data used in this study in several respects: the method for constructing hourly earnings, the apparently much greater noise in the CPS supplement data on wages than in the CPS March files, and the absence of any careful consistency checks and other edits in the employer responses to wages and other

60. See Mellow and Sider (1983); Duncan and Hill (1985); Bound and others (1989); and Bound and Krueger (1989). 
items. See Mellow and Sider for a fuller description of the data and sample design. ${ }^{61}$

Using the January 1977 CPS supplement, we estimated the sign and magnitude of the measurement error component in square brackets on the right side of equation (6) for manufacturing production workers. The data set contains 638 observations on manufacturing production workers. We deleted eleven observations because either the employeror worker-reported hourly wage was less than 75 percent of the minimum wage or greater than $\$ 250$ an hour. We deleted five additional observations because of large discrepancies between employer and worker responses that were obviously due to employer-response error. Such errors would be unlikely to survive the data checks used in the development of the LRD.

Using the remaining 622 observations, we computed the measurement error component in equation (6) and the total variance of workerreported hourly wages. The measurement error component was negative, indicating mean reversion, and equal to about 10 percent of the variance in worker-reported wages. If these results are representative of the measurement error structure in the March CPS and LRD data, then our results in table 2 understate the relative importance of withinplant wage dispersion. There is little reason, however, to think that measurement error seriously biases the time-series changes reported in table 3 .

Another potentially important source of measurement error in our between-plant, within-plant decomposition pertains only to nonproduction workers. The LRD does not contain plant-level information on hours worked per nonproduction worker. We used two different methods to impute hours per nonproduction worker in estimating plant-level hourly wages for nonproduction workers. In the first method, we computed average annual hours per nonproduction worker by two-digit industry from the March CPS files. We then applied this figure to plantlevel observations on annual earnings and nonproduction worker employment in the LRD to estimate plant-level hourly earnings for nonproduction workers. This method underlies all results in "The Role of Observable Plant Characteristics" and "Further Investigation of the Plant-Wage Structure,'” except the industry-level regressions discussed 
in footnote 55. Computed in this way, mean hourly earnings for nonproduction workers in the LRD typically exceed mean hourly earnings in the CPS by 10 to 30 percent. (For production workers, where no hours imputation is necessary, the discrepancy is only about 3 percent.) Furthermore, this first method often led to individual industry-level estimates of within-plant wage variance that were negative.

To address this difficulty, we used a second method to impute hours per nonproduction worker when carrying out the variance decomposition in "Between-Plant and Within-Plant Components of Manufacturing Wage Dispersion.' First, for each two-digit industry we computed the ratio of mean hourly wages in the LRD to mean hourly wages in the CPS for production workers. Then, we chose hours per nonproduction worker in each two-digit industry, so that the implied ratio of LRD to CPS mean hourly wages matched the corresponding ratio for production workers. This method gave sensible industry-level estimates for withinplant wage dispersion. Only one estimate (out of 132) was negative. All results in "Between-Plant and Within-Plant Components" are based on this imputation method.

Applying the imputed figure for hours per nonproduction worker to plant-level observations on nonproduction worker employment and wage bill yields an estimate for $V_{B P}^{n}$. If unmeasured cross-plant variation in hours per nonproduction worker is unrelated to mean plant wages, this procedure introduces an upward bias in the estimated $V_{B P}^{n}$ and, hence, a downward bias in $\hat{V}_{W P}^{n}$. This bias is reinforced (mitigated or reversed), if plants that pay relatively high hourly wages to nonproduction workers also have relatively high (low) hours per nonproduction worker. Using all manufacturing nonproduction workers in the January 1977 CPS supplement, we find a zero correlation between worker-reported wages and employer-reported hours and a weak positive correlation between employer-reported wages and worker-reported hours. Taken together, these observations indicate that our inability to measure plant-level variation in hours per nonproduction worker leads to an upward bias in the estimated $V_{B P}^{n}$ and a downward bias in $\hat{V}_{W P}^{n}$. 


\section{Comments and Discussion}

Comment by Lawrence F. Katz: Steve Davis and John Haltiwanger have written an excellent paper that greatly expands our knowledge of changes in the U.S. wage structure over the last twenty-five years. Previous research using household data from the Current Population Survey (CPS) has convincingly documented that overall wage inequality increased substantially from the late 1960 s to the late 1980 s and that much of this increase is accounted for by a steady expansion in wage dispersion within detailed education-experience-gender groups. This CPS-based research has raised the question of the extent to which rising wage inequality represents changes in firms' internal wage structures (that is, rising within-plant wage dispersion) as opposed to increases in wage differentials between establishments. Davis and Haltiwanger combine plant-level wage data from the Longitudinal Research Datafile (LRD) with individual-level wage data from the CPS to shed light on this and other issues concerning changes in the wage structure in U.S. manufacturing.

Davis and Haltiwanger first document that wage inequality has increased substantially inside U.S. manufacturing since 1975 and has expanded greatly among production workers in manufacturing. They then present two important new findings: a substantial part of increased wage dispersion in manufacturing reflects increased between-plant wage dispersion and the between-plant component explains the vast majority of increased wage dispersion for production workers; and wage differentials by plant size increased sharply from 1967 to 1986, and these rising size-wage differentials explain a large fraction of rising betweenplant wage dispersion for production workers. Furthermore, they estimate that the majority of the increase in wage dispersion for non- 
production workers occurred within plants. They conclude that the view that skill-biased technical change is the key factor behind rising U.S. wage inequality is consistent with these findings concerning changes in the wage structure in manufacturing and with the finding that the manufacturing sector has experienced skill upgrading that is more pronounced in large plants.

In this comment, I address three issues related to the Davis-Haltiwanger analysis. First, I discuss some data issues that indicate that there may be important inconsistencies in the data on nonproduction workers in the CPS and in the LRD. These data problems mean one needs to be cautious in interpreting the decomposition of changes in wage dispersion for nonproduction workers presented by Davis and Haltiwanger. Second, I argue that product demand shifts not confined to changes within the manufacturing sector and the outsourcing of production jobs to other countries may be an important part of the story of rising wage inequality in manufacturing. Finally, I show how data on international differences in changes in the wage structure can complement the analysis of Davis and Haltiwanger and help sort out the importance of product demand shifts, relative skill supply changes, skill-biased technological change, and institutional factors in explaining wage structure changes.

\section{Data Issues}

An important issue that arises in combining data from the LRD and the CPS to look at manufacturing employees is that the two data sets cover different sampling universes. The LRD data set used by Davis and Haltiwanger provides information on workers at production facilities. The CPS data include workers at both production facilities and nonproduction units (for example, corporate headquarters and other administrative units) and do not allow one to distinguish whether workers are employed at production or at nonproduction establishments. Although this discrepancy in coverage does not create much problem for analyzing production workers, it makes it quite difficult to interpret inferences concerning within- and between-plant changes in wages for nonproduction workers made using the Davis and Haltiwanger methodology.

The basic problem is that the measure of between-plant wage dis- 
persion for the LRD is for nonproduction workers at production facilities, but the overall measure of wage dispersion for nonproduction workers from the CPS includes nonproduction workers at both production and administrative (nonproduction) units. Davis and Haltiwanger estimate within-plant wage variance for nonproduction workers as a residual given by the difference between the overall wage variance for nonproduction workers from the CPS and the between-plant wage variance from the LRD. The problem with this approach is that it neither generates a measure of overall within-plant variance for nonproduction workers nor a measure of within-plant variance for the subset of nonproduction workers employed at production facilities, but it generates a hybrid measure containing both within- and between-establishment components of wage variance.

More formally, the variance of wages for nonproduction workers in manufacturing computed from the CPS can be decomposed as

$$
\begin{aligned}
V^{n} & =\delta V^{n n}+(1-\delta) V^{n p}+\delta(1-\delta)\left(W^{n n}-W^{n p}\right)^{2} \\
& =\left(V_{b p}^{n n}+V_{w p}^{n n}\right)+(1-\delta)\left(V_{b p}^{n p}+V_{w p}^{n p}\right)+\delta(1-\delta)\left(W^{n n}-W^{n p}\right)^{2},
\end{aligned}
$$

where $\delta$ denotes the share of employment of nonproduction workers in administrative (nonproduction) units, $V^{n n}$ denotes the variance of wages of nonproduction workers in administrative units, $V^{n p}$ denotes the variance of wages of nonproduction workers in production facilities, $W^{n n}$ is the mean wage of nonproduction workers in administrative units, $V_{b p}^{n n}$ is the variance of mean nonproduction worker wages across nonproduction establishments, $V_{w p}^{n n}$ is the mean variance of nonproduuction worker wages within nonproduction establishments, and the remaining terms denote analogous qualities for nonproduction workers in production facilities. The Davis-Haltiwanger measure of "within-plant" variance of wages for nonproduction workers $\left(V_{w p}^{n^{*}}\right)$ is given by

$$
\begin{aligned}
V_{w p}^{n^{*}} & =V^{n}-V_{b p}^{n p} \\
& =\delta\left(V_{b p}^{n n}+V_{w p}^{n n}\right)+(1-\delta) V_{w p}^{n p}+\delta(1-\delta)\left(W^{n n}-W^{n p}\right)^{2}-\delta V_{b p}^{n p},
\end{aligned}
$$

where $V^{n}$ is estimated from the CPS and $V_{b p}^{n p}$ is estimated from the LRD. Changes in this residual wage dispersion measure will not only pick up changes in within-plant dispersion for nonproduction workers at production facilities but will also pick up within- and between-plant changes 
for nonproduction workers at administrative units and changes in the wage gap between nonproduction workers at administrative units and at production facilities. Since the relative compensation of executives and professionals that are likely to be employed at administrative units has increased greatly in the 1980 s, between-plant changes between administrative units and production units could be important.

The potential practical significance of the problems in decomposing wage variance for nonproduction workers following the DavisHaltiwanger approach depends on the magnitude of $\delta$, the share of nonproduction workers in the CPS that are not captured by the LRD sampling universe. I have attempted to assess the magnitude of $\delta$ by calculating the share of nonproduction workers in total employment in manufacturing using both the CPS and the Annual Survey of Manufacturers (the aggregate data from the LRD) for 1979. Tabulations using the full-year outgoing rotation groups for the CPS in 1979 indicate that 32.7 percent of all manufacturing workers were nonproduction workers while the analogous figure for the ASM is 26.4 percent. ${ }^{62}$ If we assume that both the CPS and LRD cover all production workers, this implies that 35.9 percent of all the nonproduction workers in the CPS are missed by the LRD. This implies an estimate of $\delta$ of about 0.36 and suggests that unmeasured systematic differences in wage movements in administrative units and production facilities could greatly affect the DavisHaltiwanger estimate of within-plant wage dispersion for nonproduction workers. The likelihood of this type of discrepancy is highlighted by the fact that the nonproduction/production worker relative wage ratio increased sharply in the CPS and did not increase much at all in the ASM-LRD data from the late 1970 s to $1986 .{ }^{63}$

I conclude that the discrepancies in the sampling frames for the CPS and LRD make decomposition of wage variance changes for nonproduction workers and for all manufacturing workers quite difficult to interpret. Davis and Haltiwanger present convincing evidence that increases in between-plant wage dispersion are important for production workers. However, their estimates of the importance of changes in

62. All workers in manufacturing working in professional and technical, managerial and administrative, clerical, sales, and service occupations were designated nonproduction workers in the tabulation from the CPS.

63. Bound, Griliches, and Berman (1990). 
between-plant and within-plant dispersion for nonproduction workers are quite questionable and likely to overestimate substantially the importance of within-plant dispersion changes.

A further data issue raises some questions about the findings presented in the final sections of the Davis and Haltiwanger paper concerning changes in the structure of average hourly wage rates across plants for nonproduction workers. This issue involves the procedure used by Davis and Haltiwanger to calculate hourly wages for nonproduction workers. The LRD data do not include measures of hours worked or hourly wages for nonproduction workers. They only contain information on annual payroll for nonproduction workers and a measure of the total employment of nonproduction workers at a single point in time during the year. Davis and Haltiwanger compute hourly wages for nonproduction workers by imputing annual hours worked by industry for nonproduction workers using March CPS data. The problem with this approach is that workers with unemployment and other part-year workers are included in the calculation of average hours for nonproduction workers in an industry. Since the LRD employment data give employment at a point in time (a proxy for the average level of employment during the year) and not the total number of workers who worked in the industry during the year, the Davis-Haltiwanger approach underestimates annual hours worked by nonproduction workers in the industry. This underestimate of annual hours generates a severe overestimate of average hourly wages that is illustrated by the fact (noted by Davis and Haltiwanger in their appendix B) that the estimated hourly wage rates for nonproduction workers in the LRD are 10 to 30 percent higher than those in the CPS. This is quite surprising given the LRD is missing the high-paid workers in corporate headquarters and administrative units that are picked up in the CPS. An alternative approach to imputing average annual hours is to use fifty-two times the usual average weekly hours of nonproduction workers in manufacturing in the CPS outgoing rotation groups. I have found that this procedure yields average hourly wages for nonproduction workers that are quite comparable to the CPS. Since the bias in the Davis-Haltiwanger measure of hourly wages for nonproduction workers will vary by industry and over time, the unknown properties of this bias mean one must be cautious in interpreting any of their findings concerning the structure of average hourly wages by plant for nonproduction workers. 
In summary, the findings of Davis and Haltiwanger concerning changes in the wage structure for nonproduction workers are suspect because of data inconsistencies between the CPS and LRD and because of an inappropriate approach taken to imputing hourly wage rates in the LRD. Their results concerning the wages of production workers are not subject to these criticisms and represent the important contribution of their paper.

\section{Alternative Interpretations of Changes in the Wage Structure in Manufacturing}

Davis and Haltiwanger argue that skill-biased technical change in the manufacturing sector provides a coherent explanation for sharp increases in overall wage inequality and in wage differentials by skill and plant-size and for a substantial rise in the share of more-educated and skilled workers employed in manufacturing. Although this is a plausible story, they present no persuasive direct evidence of this type of technical change. Davis and Haltiwanger mention in their conclusion that an explanation based on increased "outsourcing"' (in which portions of industry production are sent to other countries) is also potentially consistent with their results. Borjas, Freeman, and Katz find that increases in import penetration and shifts in employment toward nonproduction workers were positively correlated for four-digit manufacturing industries over the 1960 to 1985 period. ${ }^{64}$ This finding would be directly predicted by an outsourcing explanation and is a bit more difficult to reconcile with an explanation focusing on skill-biased technical change.

An alternative explanation emphasizes the role of product demand shifts toward more skill-intensive industries outside the manufacturing sector. Davis and Haltiwanger find little evidence in favor of explanations for rising skill differentials that emphasize between-industry shifts in product demand within the manufacturing sector. However, the share of employment in manufacturing fell drastically in the United States during the 1970s and 1980s. Employment also shifted steadily over this period into industries employing more highly educated work-

64. Borjas, Freeman, and Katz (1991). 
ers. These changes suggest that labor-demand shifts outside the manufacturing sector and between manufacturing and the rest of the economy could be an important part of an explanation. In fact, Katz and Murphy estimate that both between-industry and within-industry shifts in labor demand have played significant roles in increasing the relative demand for more educated workers since the late 1960s. ${ }^{65}$ Between-industry shifts in labor demand could be associated with product-demand shifts across industries, shifts in net international trade, or with differences in factor-neutral total productivity growth across sectors. Withinindustry shifts in labor demand can be generated by skill-biased technical change or by outsourcing. The increase in the relative employment of highly skilled workers within detailed manufacturing industries and individual manufacturing plants despite the increase in the relative price of highly skilled workers indicates that some role for a relative demand shift arising from skill-biased technological changes or outsourcing is needed. The findings of Katz and Murphy on measured-demand shifts combined with the findings of Davis and Haltiwanger offer an explanation for rising skill differentials in manufacturing that should emphasize relative demand shifts arising from product market shifts against industries employing less-skilled workers combined with a role for either skill-biased technical change or outsourcing.

\section{International Differences in Changes in the Structure of Wages}

Davis and Haltiwanger have helped shed light on alternative explanations for changes in the U.S. wage structure by adding information from establishment-level data to the existing stock of knowledge based on household data. A complementary approach to evaluating different hypotheses is to expand the number of observations by adding information on changes in wage structures in other advanced industrial economies. An explanation based on skill-biased technological change implies that changes in the wage structure similar to the United States should also have occurred in other countries, such as Japan and Canada, that are likely to have been similarly affected by technological advances. Differences in changes across countries can also help illuminate the

65. Katz and Murphy (1990). 
importance of labor market institutions and of trade and other product market shifts in affecting wage structure changes.

Existing studies provide some information on international differences in overall changes in wage structure across countries. Katz and Revenga find that Japan had almost no increase in education differentials in the 1980 s and only a small increase in overall wage dispersion for males. ${ }^{66}$ Since Japan also ran a large trade surplus and maintained a steady share of employment in manufacturing over this period, the much smaller increase in skill differentials in Japan than in the United States is suggestive of an important role of product market shifts and the trade deficit in explaining the sharp rise in U.S. skill differentials in the 1980s. Freeman and Needles present evidence that Canada also had a much more moderate increase in the college-high school wage differential and in overall wage inequality than the United States in the $1980 \mathrm{~s} .{ }^{67}$ Freeman and Needles conclude that differences in growth rate in the relative supply of more-educated workers and differences in U.S. and Canadian wage-setting institutions (for example, the stable and high unionization rate in Canada versus the low and declining unionization rate in the United States) help explain divergent wage structure patterns in the United States and Canada. Finally, both Great Britain and France experienced sharp declines in manufacturing employment in the 1980s. Great Britain experienced tremendous increases in skill differentials and wage dispersion in the 1980s, while France experienced almost no increase in wage inequality. ${ }^{68}$ Increased wage dispersion in Britain coincided with sharply declining unionization, while a relatively stable French wage structure coincided with a high and pervasive minimum wage and a policy of contract extensions that prevented the relative wages of the unskilled from falling significantly, despite substantial employment declines.

These international differences suggest that relative demand shifts from product market shifts and from skill-biased technical changes have created economic pressures toward increased skill differentials throughout countries in the Organization for Economic Cooperation and Development, but the extent to which these pressures translate into wage

66. Katz and Revenga (1989).

67. Freeman and Needles (1991).

68. Katz and Loveman (1990). 
structure changes is likely to depend greatly on the nature of a country's wage-setting institutions. The extent to which the substantial divergence in wage structure change across countries in the 1980s is explained by differences in shocks as opposed to differences in institutions is an important topic for future research and could be greatly facilitated by international comparative work that followed the fruitful approach taken by Davis and Haltiwanger of linking household and establishment data on wage structures.

Comment by Robert Topel: Steve Davis and John Haltiwanger have produced a good and informative paper, based on a tremendous amount of data and analysis. In a nutshell, the paper uses largely untapped data on wages and employment at manufacturing plants to shed light on competing theories of rising wage inequality in the United States. In the end, they lean toward skill-biased technical change as the most plausible explanation for rising wage differences between skilled and less-skilled workers. Like Davis and Haltiwanger, I find that explanation attractive. Yet I don't think that their evidence (or anyone else's, so far) is definitive on the reason for rising wage inequality.

Analysis of employment and earning records for individuals in the Current Population Surveys (CPS) yields several important facts about the evolution of wages and employment in the United States. The one emphasized by Davis and Haltiwanger is that measured wage inequality has risen dramatically since 1970 . While the real wage of the median worker has remained nearly constant since 1973, real wages of persons in the first decile of the wage distribution have fallen by about 20 percent. These "price' movements are a useful point of departure for this paper, but they are only half the story. Conformable data on quantities establish that changes in relative labor demands for skilled and less-skilled workers are at work: employment, participation, and unemployment have remained stable for persons with wages in the upper half of the wage distribution, but unemployment and withdrawal from the labor force have risen substantially among less-skilled workers, for whom wages have been falling. The combination of these facts is important to keep in mind: The issue is not whether the relative demands for skilled and unskilled people have changed - they did-but rather what caused them to change.

Given this background, Davis and Haltiwanger consider four poten- 
tial explanations for rising inequality. They are (1) changes in labor demand generated by skill-biased technical change; (2) changes in labor demand owing to important competition in goods produced by lessskilled workers; (3) changing social norms; and (4) declining unionism. Explanations (1) and (2) are demand based, and so they are potentially consistent with the price and quantity movements mentioned above. Points (3) and (4) have much different predictions about changes in relative quantities, however.

The key hypothesis underlying the social norms and unionism rationales is that, in earlier times, social or union pressure forced employers to compress the distribution of wages relative to the distribution of productivities. As a result, less-skilled people earned rents. Removing these constraints is like eliminating a tax on employing less-skilled persons. Their wages should fall (which they did), but without any changes in demand, the employment of less-skilled persons should rise. Since there is no doubt that employment opportunities for less-skilled people have deteriorated, I think that these explanations can be ruled out from the start. In light of this, the remainder of my comments will focus on hypotheses (1) and (2), though there may be other, unstated, explanations that also generate changes in relative labor demands by skill group. The relevant question is, Can we distinguish between competing demand-based theories of rising inequality? I think we can, but I'm not convinced that Davis and Haltiwanger have done it.

The Longitudinal Research Datafile (LRD) used in the paper contains a menu of information on the characteristics of sampled plants, ranging from size (here, the number of employees) to capital intensity. Given the necessity of demand-based explanations for rising inequality, what can these data tell us? From my reading, Davis and Haltiwanger have identified seven major findings from the LRD and related data:

- Interindustry wage differentials. Using available controls for individual characteristics in the CPS and plant characteristics from the LRD, Davis and Haltiwanger find that the unexplained variance in industry wage differentials is rising in the CPS (after 1975) but declining in the LRD. In the LRD, they find a very sharp decline in the unexplained variance of industry wages between 1967 and 1972. They also conclude that observable plant characteristics explain substantially more of interindustry wage differentials than do the usual observables about individuals that are available in survey data. 
-Firm size for a typical worker. According to calculations by Davis and Haltiwanger, the size of the firm in which a typical employee works - the coworker mean, in their language-has fallen dramatically since the 1960s. The largest component of this fall occurs between the manufacturing census years of 1967 and 1972. In fact, the number of coworkers in the typical manufacturing worker's plant has remained fairly stable since 1972 , after falling by about 30 percent in the previous five years.

- Increased skill intensity in manufacturing. The ratio of skilled to less-skilled workers in the manufacturing sector has increased more rapidly than in the work force as a whole.

-Wage dispersion among production and nonproduction workers. Most of the overall dispersion in production worker wages is between plant; there is substantial homogeneity in wages for workers in the same plant. In contrast, most of the variance in nonproduction worker wages is within plant, indicating substantially more heterogeneity of "nonproduction" activities. Similarly, over time, nearly all of the growth in the dispersion of production worker wages is accounted for by growth in between-plant differences, while rising within-plant variance accounts for most of the increase in wage inequality among nonproduction workers.

- Increasing effects of firm size on wages. Workers in large firms earn more. This is true for both production and nonproduction workers. Starting around 1967, the relationship between firm size and wages increased steadily over time. The effects of firm size are reduced after controlling for various observable characteristics of plants and workers, but the trend is still there.

-Effects of observable plant characteristics on wage dispersion. A regression decomposition shows that changes in the distribution of observable characteristics $(X)$ across plants had very little impact on betweenplant wage inequality. In contrast, the implicit "prices" of those observables $(\beta)$ changed substantially, accounting for two-thirds of the increase in wages between the first and ninth deciles of the wage distribution. Among these, changing plant size is by far the most important observable, accounting for 40 percent of the overall change.

-Effects of international trade on wages. Changes in industry shares of imports or exports appear to have very small effects on relative industry wages. These variables are also unsuccessful in explaining the 
increase in the relationship between wage and plant size, mentioned above.

Based on these points, Davis and Haltiwanger reject product-specific demand shifts, including those generated by changing patterns of international trade, as important factors in explaining rising wage inequality in the United States. Points 2 and 3-declining firm size combined with rising quality of the work force in large plants-are key to this conclusion: if product demand shifts favor skill-intensive goods, and those are produced in large plants, then average plant size should have risen. Instead, it fell dramatically. I think their conclusion about the importance of technical change is probably right, but I am unpersuaded by their evidence.

One reason for my doubts is shown in figure 4B, which shows a stunning (nearly 30 percent) decline in average firm size in manufacturing between 1967 and 1972, followed by fluctuations about a fairly stable mean. The "coworker mean"' statistic shown in the figure is a measure of average firm size that weights each plant by its own size in calculating a mean, analogous to length-biased sampling in the analysis of duration data. As it turns out, there is a fixed relationship between the coworker mean (the number of workers in the typical worker's plant) and the average size of all plants. The relationship is

$$
m_{c}=m_{f}\left(1+s^{2}\right),
$$

where $m_{c}$ is the coworker mean, $m_{f}$ is the unweighted average size of a plant, and $s^{2}$ is the squared coefficient of variation of (unweighted) plant size.

It is clear from this equation that errors in measuring the size of individual plants will increase $m_{c}$ by increasing the measured variance of plant size. In light of this, it troubles me that there is an almost exact relationship between $m_{c}$ and the estimated standard deviation of plant size across workers, as illustrated in figure 4B. I would not be surprised if $m_{f}$ is nearly constant through time. Add to this the fact that 1967 and 1972 are census years in which sampling procedures and definitions can be revised, and the potential for greater measurement error in plant size before 1972 is obvious. My fear is that the intercensus decline in the coworker mean is largely an illusion. Two related points about measurement error are also worth making. First, declining measurement error may account for the sharp increase in the firm-size wage premium 
that is documented in the paper. Second, if the 1967-72 decline in $m_{c}$ results from errors in measuring firm size, the unexplained variance in industry wage differentials should decline sharply because firm size is an explanatory variable for these regressions. Figure 2 shows a large decline in unexplained variance between 1967 and 1972.

Even if the decline in firm size is real, its connection to technical change and rising wage inequality is tenuous. Virtually all of the decline in measured firm size occurred between 1967 and 1972, but it is well known that the trend toward greater wage inequality only began in the early 1970s, and it accelerated in the 1980s. Thus firm size was fairly stable during the period of rising inequality. This fact substantially weakens Davis and Haltiwanger's argument that the shift in the distribution of hours toward small plants helps to distinguish product demand from technical change explanations of rising wage inequality, or that changes in firm size have much at all to do with rising inequality.

Imports as a percentage of gross national product rose sharply in the 1980s. This timing corresponds fairly well with the apparent change in the relative price of skilled workers. This timing is the main evidence cited by those who believe that the internationalization of product markets has had important impact on relative wages of different skill groups. Yet Davis and Haltiwanger find very small effects of import penetration on industry-specific wages, which might be regarded as direct evidence against a trade-based explanation for rising inequality. The usefulness of this evidence is severely limited, however; it relies on the assumption that individual industries face upward sloping supply curves of labor, at least in the short run. Otherwise demand shifts should not have any effect on relative wages among industries, though they will change the relative wages of different skill groups in the overall labor market. And that is what we observe. Thus another interpretation of the evidence is that labor is sufficiently mobile that wage differences among industries are arbitraged fairly quickly, though product-specific changes in demand have economywide effects on relative wages.

Given these points, is it possible to distinguish between product demand shifts and skill-biased technical change as explanations for rising inequality? I think so, and the data analyzed by Davis and Haltiwanger contain sufficient information to do it. If changing patterns of imports and exports are the main sources of shifting demand, then the industry detail on imports and exports indicates where the demand shifts 
have occurred. This underlies the wage regressions in table 10 of the paper. Industries where imports have grown should show declining shipments and employment, and I have little doubt that they do. According to the theory, these changes are large enough to generate an economywide decline in the relative wages of less-skilled workers, who are disproportionately employed in the production of traded goods. For nontraded goods, where exports and imports are small, the change in relative wages implies skill downgrading (or at least no upgrading) because unskilled labor has become cheaper. Given the overall increase in skill ratios in manufacturing, I seriously doubt that happened. This suggests that Davis and Haltiwanger are probably right: skill-biased technical change has been a major factor affecting relative wages. This finding does not suggest that product demand shifts have been unimportant, but they cannot be the only factors at work.

I have a final point concerning the determinants of wage differentials across size classes or industries in the CPS and LRD data. As Davis and Haltiwanger note, these differences have been a source of some controversy in recent literature. Some have argued that these wage differentials reflect an equilibrium sorting of workers with heterogeneous skills, while others interpret them as rents that remain unarbitraged by competition. Davis and Haltiwanger's interpretation of the data relies on the notion that wage differentials across industries or size classes of firms reflect sorting according to skills. Then rising inequality of industry wage differences (figure 2 , in the CPS) or rising size differentials (table 6 and figure 5) are consistent with an increase in the relative demand for skilled labor.

This pattern suggests a potential test of the sorting hypothesis. If the skills demanded by different industries have been relatively stable over time, then workers in, say, the steel industry should be in about the same relative position in the wage distribution today that they were in in 1970. For example, if in 1970 the typical steel worker was from the seventy-fifth percentile, then skill-biased sorting suggests that wages of steel workers will rise by the same relative amount as all workers in the seventy-fifth percentile. This method generates predicted industry or size-related wage differentials in the 1980 s, based on the historical distribution of skills and the change in skill prices over time. If observed changes in wage differentials can be replicated by this method, it would be strong evidence that cross-sectional differences in wages by size or 
industry are determined by differences in productivities of workers. This is surely a worthwhile exercise.

General Discussion: Several of the participants were concerned with the quality of the data used in the paper. Zvi Griliches noted that the data used to determine within-plant wage dispersion were assembled from two incompatible data sets-the LRD and CPS. In response, Steve Davis said that he and John Haltiwanger devoted much effort to investigating issues related to the quality and compatibility of the data. He stressed three points. First, for production workers, the CPS and LRD provide closely compatible compensation and hours measures, and the two data sets deliver similar mean wage measures for overall manufacturing and for detailed industries. The compatibility of the two data sets is a much more serious problem for nonproduction workers, as explained in the appendixes. Second, provided that the measurement error structure in the two data sets is stable through time, the timeseries changes in the within-plant wage variance reported in table 3 are unbiased. Third, in appendix B Davis and Haltiwanger review the evidence on the structure of measurement error that emerges from studies of matched employer-worker data sets. They find that the available evidence is consistent with the identifying assumptions that underlie their procedure for estimating the within-plant wage variance.

Bronwyn Hall wondered about the accuracy of hours data for nonproduction workers in plants with fewer than nineteen employees. She suggested that such workers who were reporting 2,000 hours of work a year might really only be working part time. Martin Baily disagreed with Hall, saying that she was implying that small business proprietors do not work very hard.

Robert Hall said that the data on plant size might be unreliable because of the way in which firms define their plants. He claimed that firms, often for administrative purposes, will designate one physical location as consisting of more than one plant. Steve Davis said in the LRD data one physical location is generally defined as a single plant. Robert McGuckin admitted that if different products were produced in the same geographical location, it would be possible for the data to show more than one plant, but he said that treatment of this would be consistent over time in the data set and that the census has procedures 
to split plants if the products produced at a single location fall into multiple SICs.

Robert Hall also wondered about the meaningfulness of the authors' distinction between production and nonproduction workers. He said that on the shop floors of modern high-tech factories, production and nonproduction workers are likely to be indistinguishable. Hall claimed that in these types of factories "everybody wears a jacket and tie and some of them tend certain kinds of machines and some of them tend computers.' 'Hall asserted that in modern factories both production and nonproduction workers are involved in problem solving. He went on to say that in the transformation of the U.S. economy from a "hardware" economy to a problem-solving one, the losers in the work force have been those not good at solving problems.

Frank Levy wondered about the real meaning of skill-biased technical change. Skill, he said, is not related to education in any simple way, because when there was a glut of college-educated workers in the 1980s, the within-group return to skill for this group was rising. According to Levy, automobile plants that make a transformation from the American to the Japanese manufacturing system (such as the California NUMMI factory) have achieved significant gains in productivity while using the same workers. Levy said this suggests that the productivity situation in these plants has more to do with managerial ability or some other kind of sunk-cost technology than with skills the workers bring to the factory gates.

Bronwyn Hall said that the observed plant-size wage differentials might reflect a firm size effect. In response to this, Lawrence Katz said there does not seem to have been an increase in wage differential by firm size from 1979 to 1988 .

\section{References}

Abowd, John M., and Richard B. Freeman. 1990. "Internationalization of the U.S. Labor Market." Working Paper 3321. Cambridge, Mass.: National Bureau of Economic Research (NBER).

Bailey, Thomas. 1989. "Changes in the Nature and Structure of Work: Implications for Skills and Skill Formation." Mimeo, Columbia University (November).

- 1990. "Economic Change, Organizational Innovation, and Escalating 
Skill Requirements." Paper presented at the Conference on Changing Occupational Skill Requirements. Brown University.

Blackburn, McKinley L., David E. Bloom, and Richard B. Freeman. 1990. "The Declining Economic Position of Less Skilled American Men." In The Changing Structure of U.S. Wages, edited by Gary Burtless. Brookings.

Bluestone, Barry. 1989. "The Changing Nature of Employment and Earnings in the U.S. Economy, 1963-89.' Mimeo, University of Massachusetts at Boston (April).

Bluestone Barry, and Bennet Harrison. 1988. "The Growth of Low-Wage Employment: 1963-86." American Economic Review, Papers and Proceedings, 1987 78(May):124-28.

Borjas, George J., Richard B. Freeman, and Lawrence F. Katz. 1991. “On the Labor Market Effects of Immigration and Trade." In The Determinants and Effects of Immigration on the U.S. and Source Economies. University of Chicago Press, forthcoming.

Bound, John, Zvi Griliches, and Eli Berman. 1990. "Changes in the Demand for Skilled Labor within U.S. Manufacturing Industries: Evidence from the Annual Survey of Manufacturing." Unpublished Paper. Harvard University (December).

Bound, John, and others. 1989. "Measurement Errors in Cross-Sectional and Longitudinal Labor Market Surveys: Results from Two Validation Studies." Working Paper 2884. Cambridge, Mass.: NBER.

Bound, John, and George Johnson. 1989. "Changes in the Structure of Wages during the 1980s: An Evaluation of Alternative Explanations." Working Paper 2983. Cambridge, Mass.: NBER.

Bound, John, and Alan Krueger. 1989. "The Extent of Measurement Error in Longitudinal Earnings Data: Do Two Wrongs Make a Right?' Working Paper 2885. Cambridge, Mass.: NBER.

Brown, Charles, and James Medoff. 1989. "The Employer Size Wage Effect." Journal of Political Economy 97 (October):1027-59.

Curme, Michael A., Barry T. Hirsch, and David A. Macpherson. 1990. "Union Membership and Contract Coverage in the United States, 1983-88.' "Mimeo, Florida State University.

Davis, Steve J. 1990. "Size Distribution Statistics from County Business Patterns Data." Mimeo, University of Chicago (September).

Davis, Steve J., and John Haltiwanger. 1989. “The Distribution of Employees by Establishment Size: Patterns of Change and Comovement in the United States, 1962-85.' Mimeo, University of Chicago and University of Maryland (November).

Duncan, Greg, and Daniel Hill. 1985. "An Investigation of the Extent and Consequences of Measurement Error in Labor-Economic Survey Data." Journal of Labor Economics 3 (October):508-32. 
Dunne, Timothy, and Mark J. Roberts. 1990. "Wages and the Risk of Plant Closing." Discussion Paper. Washington: Center for Economic Studies (July).

Freeman, Richard B. 1980. "Unionism and the Dispersion of Wages." Industrial and Labor Relations Review 34 (October):3-23.

1982. "Union Wage Practices and Wage Dispersion within Establishments." Industrial and Labor Relations Review 36 (October):3-21.

1988. "Contraction and Expansion: The Divergence of Private Sector and Public Sector Unionism in the United States." Journal of Economic Perspectives 2 (Spring):63-88.

Freeman, Richard B., and James Medoff. 1979. "New Estimates of Private Sector Unionism in the United States." Industrial and Labor Relations Review 32 (January):143-74.

Freeman, Richard, and James Medoff. 1984. What Do Unions Do? Basic Books.

Freeman, Richard B., and Karen Needles. 1991. "Skill Differentials in Canada in an Era of Rising Labor Market Inequality." Unpublished Paper. Harvard University (January).

Gollop, Frank M., and James L. Monahan. 1989. "From Homogeneity to Heterogeneity: An Index of Diversification." Technical Paper 60. Bureau of the Census.

Groshen, Erica. 1991a. "Sources of Wage Dispersion: The Contribution of Interemployer Differentials within Industry.' Quarterly Journal of Economics, forthcoming.

1991b. "Employers, Occupations, and Wage Inequality in Three Cities, 1957-89: Another Piece of the Puzzle." Mimeo, Federal Reserve Bank of Cleveland (March).

Hamermesh, Daniel S. 1980. "Commentary." In The Economics of Firm Size, Market Structure, and Social Performance, edited by John J. Siegfried. Washington: Federal Trade Commission.

Juhn, Chinhui, Kevin M. Murphy, and Brooks Pierce. 1989. “Wage Inequality and the Rise in Returns to Skill." Mimeo, University of Chicago (November).

Katz, Lawrence F., and Gary Loveman. 1990. “An International Comparison of Changes in the Structure of Wages: France, the United Kingdom, and the United States."' Unpublished Paper. Harvard University (December).

Katz, Lawrence F., and Kevin M. Murphy. 1990. "Changes in Relative Wages, 1963-87: Supply and Demand Factors." Mimeo, Harvard University, University of Chicago, and NBER (April).

Katz, Lawrence F., and Ana L. Revenga. 1989. "Changes in the Structure of Wages: The U.S. versus Japan." Journal of the Japanese and International Economies 3 (December):522-53.

Katz, Lawrence F., and Lawrence H. Summers. 1989. “'Industry Rents: Ev- 
idence and Implications," Brookings Papers on Economic Activity, Microeconomics: 209-75.

Kokkelenberg, Edward C., and Donna R. Sockell. 1985. "Union Membership in the United States, 1973-81." Industrial and Labor Relations Review 38 (July):497-543.

Lambson, Val E. 1991. "Industry Evolution with Sunk Costs and Uncertain Market Conditions." International Journal of Industrial Organization, forthcoming.

Levy, Frank. 1989. "Recent Trends in U.S. Earnings and Family Incomes." NBER Macroeconomics Annual, vol. 4, edited by Olivier Blanchard and Stanley Fischer.

Levy, Frank, and Richard Murnane. 1991. "Earnings Levels and Earnings Inequality: A Review of Recent Trends and Proposed Explanations." Mimeo, University of Maryland and Harvard University (January).

Lewis, H. Gregg. 1986. Union Relative Wage Effects: A Survey. University of Chicago Press.

Lillard, Lee, James P. Smith, and Finis Welch. 1986. “'What Do We Really Know about Wages? The Importance of Nonreporting and Census Imputation.' Journal of Political Economy 94 (June):489-506.

Lucas, Robert E. 1978. "On the Size Distribution of Business Firms." Bell Journal of Economics 9 (Autumn):508-23.

Mellow, Wesley, and Hal Sider. 1983. " Accuracy of Response in Labor Market Surveys: Evidence and Implications." Journal of Labor Economics 1 (October):331-44.

Miller, Frederick H., Jr. 1982. "Wages and Establishment Size.” Ph.D. dissertation, University of Chicago.

Murphy, Kevin M., and Finis Welch. 1991. "Wage Differentials in the 1980s: The Role of International Trade.' Economic Inquiry, forthcoming.

Oi, Walter. 1983. "The Fixed Costs of Specialized Labor.' In The Measurement of Labor Cost, edited by Jack Triplett. University of Chicago Press.

Podgursky, Michael. 1986. "Unions, Establishment Size, and Intra-Industry Threat Effects." Industrial and Labor Relations Review 39 (January):27784.

Revenga, Ana L. 1989. "Exporting Jobs? The Impact of International Competition on Employment and Wages.' Mimeo, Harvard University (December).

Reynolds, Lloyd G., and Cynthia H. Taft. 1956. The Evolution of Wage Structure. Yale University Press.

Rosen, Sherwin. 1982. "Authority, Control, and the Distribution of Earnings." Bell Journal of Economics 13 (Autumn):311-23. 
1986. "The Theory of Equalizing Differences." In Handbook of Labor Economics, vol. 1, edited by Orley Ashenfelter and Richard Layard. Amsterdam and New York: North Holland.

Slichter, Sumner H., James J. Healy, and E. Robert Livernash. 1960. The Impact of Collective Bargaining on Management. Brookings. 